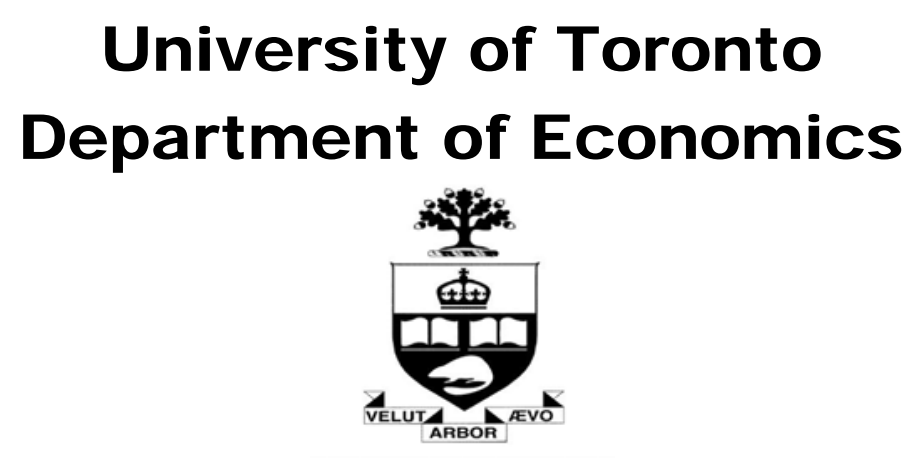

Working Paper 322

How does the marriage market clear? An empirical framework

By Aloysius Siow

July 12,2008 


\title{
How does the marriage market clear? An empirical framework.
}

\author{
Aloysius Siow \\ University of Toronto
}

July 11, 2008

\begin{abstract}
The paper surveys the Choo Siow (CS) marriage matching model and its extensions. CS derives a behavioral marriage matching function. The collective model of intrahousehold allocations can be integrated into this framework. Spousal labor supplies respond to changing marriage market conditions. Marriage market tightness, the ratio of unmarried type $i$ men to unmarried type $j$ women is a sufficient statistic for marriage market conditions for those types of individuals. The hypothesis that spousal labor supplies vary to equilibrate the marriage market has overidentifying restrictions. The framework extends to a dynamic marriage matching environment. Empirically, this paper shows how the famine caused by the great leap forward in Sichuan affected the marital behavior of famine born cohorts. Marriage market tightness is shown to be a useful statistic for summarizing marriage market conditions in the United States. Marriage market conditions in the contemporary United States primarily affect spousal labor force participation rather than hours of work.
\end{abstract}


How does the marriage market clear? An empirical framework.

Who marries whom, and how does the marriage market clear, are two classic questions in the study of marriage markets. ${ }^{1}$ There are few empirical studies on these questions because economists are just beginning to estimate bilateral matching models, and interspousal transfers in modern societies are difficult to observe. ${ }^{2}$

The objective of this paper is to survey and extend research by my coauthors and I on these two questions. Choo Siow (2006; hereafter CS) proposed and estimated a marriage matching function (MMF). A marriage matching function maps population supplies to who marries whom. The benefits of the CS MMF are: (1) It is non-parametric and easy to estimate; (2) It has behavioral foundations. ${ }^{3}$

An application of CS is in Brandt, Siow and Vogel (2008; hereafter BSV) who used it to study the effects of the famine in China caused by the great leap forward on the marital behavior of the famine born cohorts.

When agents decide who to marry or whether to marry, they have to anticipate their allocation of resources for each marital choice. To model these within marital behavior, Choo, Seitz and Siow (2008a, 2008b; hereafter CSSa and CSSb) nests the collective model of intra-household behavior with the CS framework. The collective model is an empirically tractable model of intra-household allocation where household members may have divergent interests (Chiappori (1988, 1992); Donni (2005) ; Vermeulen (2002)). Building on Blundell, Chiappori and Meghir (2005), our collective marriage matching model provides a solution to the long standing search for an empirical model of marriage matching and intra-household 


\section{How does the marriage market clear? An empirical framework.}

allocations. $^{4}$

Marriage market conditions affect inter-spousal bargaining power. What is a useful empirical proxy for marriage market conditions? Researchers have primarily focused on the own sex ratio, the ratio of population supplies of the type of the husband, $i$, to the population supplies of the type of the wife, $j$. But as the own sex ratio changes, the sex ratios of spousal substitutes are also changing. Thus ignoring the availability of spousal substitutes makes it difficult to interpret the results of these studies. We provide an alternative empirical proxy for marriage market condition, marriage market tightness, which incorporates the effects of spousal substitutes. ${ }^{5}$ Section 4.2 shows that changes in marriage market tightness affect spousal labor supplies. While we and other researchers (E.g. Angrist (2002); Chiappori, Fortin and Lacroix (2002; hereafter CFL); Grossbard-Shectman (1993)) show that changes in marriage market conditions affect spousal labor supplies, it is not known if spousal labor supplies adjust sufficiently to clear the marriage market. To answer such a question, we need to estimate a structural model of spousal labor supplies and marriage matching. CSSb proposes and estimates such a model. Section 5.2 sketches how this is done.

Another restrictive feature of CS is that it is a static MMF whereas marital behavior is fundamentally dynamic. An individual may choose to remain unmarried today in order to marry in the future. Thus we need to develop dynamic MMF's. Choo Siow (2007) begins that agenda

Finally, the empirical framework here assumes away the problem of unobserved heterogeneity. We currently do not know how to estimate equilibrium bilateral matching models 


\section{How does the marriage market clear? An empirical framework.}

with two sided unobserved heterogeneity.

Sections 1 and 2 will exposit marriage matching functions and the CS model respectively. Section 3 summarizes BSV. Section 4 presents the collective marriage matching model. Sections 4.2 and 5.2 discuss labor supplies and marriage market clearing. Section 6 sketches an overlapping generations dynamic MMF where the number of entrants into the marriage market is time varying.

\section{Marriage matching functions ${ }^{6}$}

Building on the classic model of Leslie (1945), demographers use one-sex models to empirically model population growth. However, empirical male versus female one sex models of population growth lead to contradictory implications. These contradictions arise to a large part because one sex models, by construction, do not impose consistent mating and reproductive behavior across the two genders.

In order to construct empirical two sex models of population growth, researchers have to first provide tractable empirical models of mating behavior, or who marries whom. ${ }^{7}$ Demographers construct MMFs to model who marries whom.

Let there be $I$ types of men and $J$ types of women. $M$ is a population vector where element $m_{i}$ is the number of eligible (single) type $i$ men. $F$ is a population vector where element $f_{j}$ is the number of eligible (single) type $j$ women. $\Pi$ is a vector of exogenous parameters. A marriage matching function $(\mathrm{MMF})$ is an $I \times J$ matrix $\mu(M, F$; $)$ whose $\{i, j\}$ element is $\mu_{i j}$, the number of type $i$ men married to type $j$ women: 


\section{How does the marriage market clear? An empirical framework.}

$$
\mu_{i j}=\eta_{i j}(M, F, \Pi) ; \forall i, j
$$

Let $\mu_{i 0}$ and $\mu_{0 j}$ be the numbers of unmarried type $i$ men and type $j$ women respectively.

The MMF must also satisfy the following accounting constraints:

$$
\begin{array}{r}
\mu_{0 j}+\sum_{i=1}^{I} \mu_{i j}=f_{j} \forall j \\
\mu_{i 0}+\sum_{j=1}^{J} \mu_{i j}=m_{i} \forall i \\
\mu_{i 0}, \mu_{0 j}, \mu_{i j} \geq 0 \forall i, j
\end{array}
$$

Equations (2) and (3) say that the sum of all participants for the marital choices by type $j$ women and type $i$ must sum up to the supplies of type $j$ women and type $i$ men respectively. Equation (4) says that each marital choice must have non-negative participants. The accounting constraints are important because marriage rates for some types of individuals are close to 1 . Thus MMFs which ignore accounting constraints will often result in predicted marriage rates above 1 .

Although the objective has been known for some time, it has been difficult to come up with empirically tractable and yet behaviorally attractive MMFs. ${ }^{8}$ The main difficulty is how to deal with alternative spousal choices while minimizing a priori identifying restrictions. The current standard MMF is the harmonic mean MMF (E.g. Qian and Preston (1993); Schoen (1981)):

$$
\frac{\mu_{i j}}{m_{i}}+\frac{\mu_{i j}}{f_{j}}=\pi_{i j}, \forall i, j
$$




\section{How does the marriage market clear? An empirical framework.}

$\pi_{i j}$, which represent "forces of attraction", are parameters to be estimated. This MMF

is attractive because it is non-parametric and easy to estimate. However, it has three deficiencies. First, it ignores the problem of alternative spousal choices. Changes in $m_{i^{\prime}}$ or $f_{j^{\prime}}$ do not affect $\mu_{i j}$. Second, the accounting constraints, (2) to (4), are not imposed. As shown below, this problem leads to nonsensical predicted marital behavior in an actual application. Finally, it has no coherent behavioral foundation.

\section{Choo Siow ${ }^{9}$}

CS provides a framework to derive empirically tractable and behaviorally consistent MMFs.

Start by considering each marital match between two different types of individuals as a distinct marriage market. With $I$ types of men and $J$ types of women, there are $I \times J$ submarriage markets.

In an $\{i, j\}$ marriage, a systematic marriage surplus which depends on the type of the match, $\Pi_{i j}$, is generated. Let $\widetilde{\tau}_{i j}$ be the share of the surplus that is obtained by the wife. Each type $j$ wife also gets an idiosyncratic payoff which depends on her specific identity, and the type of spouse that she marries and not his specific identity. Her idiosyncratic payoff also does not depend on $\widetilde{\tau}_{i j}$.

In an $\{i, j\}$ marriage, $\Pi_{i j}-\widetilde{\tau}_{i j}$ is the share of marital surplus that is obtained by the husband. Each type $i$ husband also gets an idiosyncratic payoff that is specific to him, and the type of spouse that he marries and not her specific identity. His idiosyncratic payoff also does not depend on $\Pi_{i j}-\widetilde{\tau}_{i j}$. The above assumptions imply that every type $i$ male regards 


\section{How does the marriage market clear? An empirical framework.}

every type $j$ female as perfect spousal substitutes and vice versa.

Each individual also gets a systematic payoff from remaining unmarried which depends on their type as well as an idiosyncratic payoff which depends on their specific identity.

Given their payoffs, both systematic and idiosyncratic, from every potential spousal choice including remaining unmarried, each individual will choose the spousal choice which maximizes their utility. Note that concern over different spousal choices are automatically built into the individual's choice problem.

Given $\widetilde{\tau}_{i j}$, we can solve each individual's spousal choice problem. We can aggregate these individual decisions into demand and supply functions for spouses in every $\{i, j\}$ submarriage market.

Finally, we solve for the matrix of $\widetilde{\tau}_{i j}$ which will equilibrate demand with supply in every submarriage market simultaneously.

The equilibrium distribution of marriages is a function of population vectors and exogenous parameters which determine the systematic and idiosyncratic payoffs. Thus this equilibrium distribution of marriages is a MMF.

This framework for constructing MMF has three benefits. First, it is behaviorally coherent. Second, considerations of alternative spousal choices are built into the framework. Third, in equilibrium, all accounting constraints, (2) to (4) are automatically satisfied.

What remains is to find convenient functional forms to implement the above framework. An important assumption in CS is transferable utilities (constant marginal utilities of income). As will be shown below, this restriction is necessary for identification if we only have 


\section{How does the marriage market clear? An empirical framework.}

marriage matching data.

Let the utility of male $g$ of type $i$ who marries a female of type $j$ be:

$$
v_{i j g}=\Pi_{i j}-\widetilde{\tau}_{i j}+\varepsilon_{i j g}
$$

As discussed above, $\Pi_{i j}-\widetilde{\tau}_{i j}$ is the systematic marital share of the husband. $\varepsilon_{i j g}$ is his idiosyncratic payoff. Assume that $\varepsilon_{i j g}$ is an i.i.d. type I extreme value random variable. ${ }^{10}$

If he chooses to remain unmarried, denoted by $j=0$, his utility will be:

$$
v_{i 0 g}=\Pi_{i 0}+\varepsilon_{i 0 g}
$$

where $\varepsilon_{i 0 g}$ is also an idiosyncratic payoff which is another i.i.d. extreme value random variable.

This man $g$ can choose to marry one of $J$ types of spouses or not to marry. The utility from his optimal choice will satisfy:

$$
v_{i g}=\max _{j}\left[v_{i 0 g}, . ., v_{i j g}, . ., v_{i J g}\right]
$$

Let $\underline{\mu}_{i j}$ be the number of type $i$ men who want type $j$ spouses. When there are many type $i$ males, McFadden (1974) showed that type $i$ 's quasi-demand for $j$ spouses satisfy:

$$
\ln \frac{\underline{\mu}_{i j}}{\underline{\mu}_{i 0}}=\Pi_{i j}-\widetilde{\tau}_{i j}-\Pi_{i 0}
$$

Turning to the marital choices of women, let the utility of female $k$ of type $j$ who marries a male of type $i$ be:

$$
V_{i j k}=\widetilde{\tau}_{i j}+\epsilon_{i j k}
$$




\section{How does the marriage market clear? An empirical framework.}

As discussed above, $\widetilde{\tau}_{i j}$ is the systematic marital share of the wife. $\epsilon_{i j k}$ is her idiosyncratic payoff. Assume that $\epsilon_{i j k}$ is an i.i.d. extreme value random variable.

If she chooses to remain unmarried, denoted by $i=0$, her utility will be:

$$
V_{0 j k}=\Pi_{0 j}+\epsilon_{0 j k}
$$

where $\epsilon_{0 j k}$ is also an idiosyncratic payoff which is another i.i.d. extreme value random variable.

This woman $k$ can choose to marry one of $I$ types of spouses or not to marry. The utility from her optimal choice will satisfy:

$$
V_{j k}=\max _{j}\left[V_{0 j k}, . ., V_{i j k}, . ., V_{I j k}\right]
$$

Let $\bar{\mu}_{i j}$ be the number of type $j$ women who want type $i$ spouses. When there are many type $j$ females, type $j$ 's quasi-supply for $i$ spouses satisfy:

$$
\ln \frac{\bar{\mu}_{i j}}{\bar{\mu}_{0 j}}=\widetilde{\tau}_{i j}-\Pi_{0 j}
$$

For every $I \times J$ submarriage market, let $\widetilde{\tau}_{i j}=\tau_{i j}$ be the female equilibrium share of marital surplus in the $\{i, j\}$ submarriage market which equilibrates the demand and supply of spouses in all submarkets simultaneously. In this case, the equilibrium number of $\{i, j\}$ marriages, $\mu_{i j}$, will satisfy:

$$
\mu_{i j}=\underline{\mu}_{i j}=\bar{\mu}_{i j} \forall i, j
$$

CSSa shows existence of marriage market equilibrium for a more general class of models. 


\section{How does the marriage market clear? An empirical framework.}

Imposing marriage market clearing, (14), to the quasi-demand equation, (9), and to the quasi-supply equation, (13), we get the male and female net gains equations respectively:

$$
\begin{aligned}
& \ln \frac{\mu_{i j}}{\mu_{i 0}}=\Pi_{i j}-\tau_{i j}-\Pi_{i 0} \\
& \ln \frac{\mu_{i j}}{\mu_{0 j}}=\tau_{i j}-\Pi_{0 j}
\end{aligned}
$$

Net gains, $\ln \frac{\mu_{i j}}{\mu_{i 0}}$ and $\ln \frac{\mu_{i j}}{\mu_{0 j}}$, are observable by the researcher. However, observing the two net gains is not sufficient to identify the four unknowns, $\Pi_{i j}, \tau_{i j}, \Pi_{i 0}$ and $\Pi_{0 j}$. Moreover, $\tau_{i j}$ is endogenous. Thus net gains will change as population supplies change.

Add the two net gains equations to get the CS MMF:

$$
\ln \frac{\mu_{i j}}{\sqrt{\mu_{i 0} \mu_{0 j}}}=\frac{\Pi_{i j}-\Pi_{i 0}-\Pi_{0 j}}{2}=\pi_{i j} \forall i, j
$$

CS calls the left hand side of (17) the total gains to marriage. It is equal to ratio of the number of marriages to the geometric average of the unmarrieds. The right hand side, $\pi_{i j}$, is equal to the systematic marital surplus of an $\{i, j\}$ marriage minus their systematic surpluses from not marrying.

$\pi_{i j}$ is fixed; it does not depend on population supplies. Moreover, the left hand side of (17) is observable. Thus we can estimate $\pi_{i j}$.

The CS MMF is non-parametric. It will fit any cross section marriage distribution as long as there is no thin cell. $\Pi_{i j}, \Pi_{i 0}$ and $\Pi_{0 j}$ are not separately identified. The discussion here assumes $\Pi_{i j}$ as a primitive. CS assumes that $\Pi_{i j}$ depends on the separate spousal contributions to marital surplus. These separate spousal contributions are not identified. 


\section{How does the marriage market clear? An empirical framework.}

There are $I \times J$ total gains and $I \times J$ unknown parameters, $\pi_{i j}$. The CS MMF is just identified.

Since not all structural parameters are identified, in what sense is CS MMF a marriage matching function? Let $\pi$ be the matrix of total gains parameters where a typical element is $\pi_{i j}$. CS shows that:

Proposition 1 Consider an equilibrium distribution of marriages, $\mu$, with population vectors $M$ and $F$, and parameter matrix $\pi$. The equilibrium distribution of marriages varies uniquely for small variations in $M, F$ and $\pi$.

The above proposition says that, for small changes in population vectors and $\pi$, the CS

MMF is a MMF as defined in section 1. The question of global uniqueness remains open. Although there are substitution effects in the CS MMF, their analytic properties are not fully understood.

The transferable utilities (constant marginal utilities of income) assumption is necessary for identification of the MMF with only marriage matching data. Without transferable utilities, parameters which determine the marginal utilities of income will also need to be identified and the MMF will be unidentified without additional restrictions. CSSa and CSSb extend the model beyond transferable utilities and bring in additional data, spousal labor supplies, to identify parameters.

Unlike Dagsvik's MMF, the CS MMF is homogenous of degree one in population supplies. Botticini and Siow (2007) provides evidence from three different societies which shows that the constant returns to scale assumption for marriage markets is reasonable. CS uses the MMF to study how the legalization of abortion in the United States affected the demand for 


\section{How does the marriage market clear? An empirical framework.}

marriage. Choo Siow (2006a) uses it to study marriage and cohabitation in contemporary Canada.

Although not discussed in CS, another result is immediate. Subtract male net gains, (15), from female net gains, (16), to get:

$$
\tau_{i j}=\frac{1}{2} \ln \frac{\mu_{i 0}}{\mu_{0 j}}+\frac{\Pi_{i j}+\Pi_{0 j}-\Pi_{i 0}}{2}
$$

$\ln \frac{\mu_{i 0}}{\mu_{0 j}}$ is the $\log$ ratio of the equilibrium number of unmarried type $i$ men to unmarried type $j$ women. We call $T_{i j}=\ln \frac{\mu_{i 0}}{\mu_{0 j}}$ marriage market tightness. $T_{i j}$ summarizes marriage market conditions for the $\{i, j\}$ match.

Equation (18) implies:

Proposition 2 Holding marital outputs, $\Pi_{i j}, \Pi_{i 0}$ and $\Pi_{0 j}$, constant, the equilbrium share of marital output which accrues to the wife, $\tau_{i j}$, is increasing in marriage market tightness, $T_{i j}$.

Finally,

Proposition 3 For every $\{i, j\}$, the net gains equations, (15) and (16), imply (17) and (18) and vice versa.

\section{$3 \quad$ Famine and marriage in China ${ }^{11}$}

An economic and social experiment, the great leap forword in 1959-1961, resulted in the largest 20th century famine in China. The famine drastically reduced the birth rates in those years thereby affecting the sex ratio for customary spousal age difference for the famine affected birth cohorts.

Sichuan province was hard hit by the famine which also disproportionately affected the countryside. Figure 1 shows the number of individuals in rural Sichuan by age in 1990. The 


\section{How does the marriage market clear? An empirical framework.}

figure shows, between the two vertical lines, that there were substantially fewer individuals between ages 29 to 31, who were born during the great leap, relative to adjacent ages. Figure 2 shows that the sex ratio (ratio of men to women) of the famine born cohorts did not substantially change relative to their adjacent age cohorts. However the sex ratios at the customary spousal age difference (males being three years older) for the famine affected cohorts were substantially affected. Famine born men and women faced a surplus of their customary aged spouses. On the other hand, pre famine born men and post famine born women faced a deficit of their customary aged spouses.

[Insert Figures 1, 2, 34 here]

Figure 3 and 4 show the 1990 male and female marriage rates by age respectively. For both genders, the marriage rates of the famine affected cohorts were relatively small. Small marriage rate changes are consistent with what other researchers have found with other large exogenous demographic changes. This finding led previous researchers to argue that individuals are flexible in their spousal choice (E.g. Bergstrom and Lam (1994); Bhrolchain (2001); Esteve and Cabré (2004)).

Since famine born cohorts were small relative to adjacent aged birth cohorts, small changes in their marriage rates imply that they were "discriminated" against in the marriage market. In other words, marital surpluses with famine born spouses must have been low relative to other types of spouses. If their marital surpluses did not change, their marriage rates should have increased, particularly for men, because there was room to increase. As Gorgens et. al. (2005) has shown, famine born individuals have suffered adverse health consequences 


\section{How does the marriage market clear? An empirical framework.}

due to the famine. Thus their attractiveness as spouses was also likely to have suffered.

The observed marriage rates were due to a combination of population changes and changes in marital surpluses. To disentangle the two effects, we need to predict what would have been the change in marital behavior due to population changes alone. To this end, we estimated the harmonic mean and the CS MMFs using the 1982 census. The type of an individual is associated with his or her age. In 1982, the marital behavior of 29-31 year olds would not have been affected by the famine. ${ }^{12}$ Using the estimated 1982 marriage matching parameters, we predicted what the marriage rates in 1990 would have been using 1990 population vectors.

Figures 3 and 4 show the predicted male and female marriage rates from the two models respectively. For both genders, the predicted marriage rates from the harmonic mean MMF often exceed 1, a nonsensical result. These violations occurred because the harmonic mean MMF does not impose the required accounting identities, spousal substitution effects are absent, and the changes in sex ratios of customary spousal age differences were large. Thus as previous researchers have observed, the standard MMF used by demographers is a poor empirical MMF.

On the other hand, the predicted marriage rates from the CS MMF behave sensibly. In figures 3 and 4 , the predicted marriage rates are above average for the famine born cohorts and below average for the adjacent aged birth cohorts. No accounting constraint is violated. Note that actual female marriage rates were over 0.95 for most ages. Even with large changes in sex ratios of the customary spousal age differences for the famine born cohorts, their predicted marriage rates remained below 1. The predicted female marriage 


\section{How does the marriage market clear? An empirical framework.}

rates for famine born cohorts were very similar to those predicted for adjacent aged cohorts. In other words, the CS MMF respects both the accounting constraints of MMFs and also captures the flexibility of individuals in their marital choices. These two attributes show the advantage of the CS MMF over the harmonic mean MMF.

In figure 3, famine born males had lower marriage rates than predicted and pre famine born males had higher marriage rates than predicted. These two features are explained by the hypothesis that famine born males generated lower marital surpluses than pre famine born males. In other words, famine born males had lower total gains to marriage than their 1982 same aged peers.

Figure 4 shows that the discrepancies between predicted and actual female marriage rates were small. These small discrepancies obscure the changes in total gains to marriage for famine born females. The discrepancies between predicted and actual male marriage rates show that total gains in 1990 changed substantially from 1982 estimated total gains. BSV showed that predicted marital matches in 1990 were different from actual marital matches. Thus the small discrepancies between predicted and actual female marriage rates in 1990 obscure estimated changes in total gains to marriage between 1982 and 1990 for famine affected birth cohorts.

BSV also estimated a CS MMF where the type of an individual was defined by their education and age. The predicted 1990 marriage rates were not significantly different from the simpler model where type depended only on age. 


\section{How does the marriage market clear? An empirical framework.}

\section{The collective marriage matching model}

Economists have developed empirical models on intra-household allocations. A benchmark model is the collective model. The attractive feature of the collective model is that it is an empirically tractable model of intra-household allocation where intra-household bargaining power plays a central role in determining the allocation. An open question is whether the collective model can be embedded into an equilibrium marriage matching framework. CSSa and CSSb answer this in the affirmative. We show how the collective model can be embedded into the CS marriage matching framework. In addition, we also extend the CS model beyond transferable utilities.

Again, consider a society in which there are $I$ types of men and $J$ types of women, and population vectors $M$ and $F$. Individuals choose who to marry if they want to marry and also the type of marriage they want to engage in. An $\{i, j, s\}$ marriage is a marriage between a type $i$ man and a type $j$ woman in a $s$ type living arrangement. A living arrangement may depend on whether the couple is cohabitating or formally married, whether the wife works or not, whether they have children or not, etc.

At the time of marriage, wages and non-labor income for each household are known. We normalize the prices of all consumption goods to one. Each household has to choose spousal labor supplies, public and private consumption. The rationale for including public good consumption within marriage is to capture resources allocated to children in the marriage.

Consider an $\{i, j, s\}$ marriage. Let $C_{i j s}\left(c_{i j s}\right)$ be the private consumption of the wife (husband), $K_{i j s}$ the household's expenditures on public goods and $H_{i j s}\left(h_{i j s}\right)$ the wife's 


\section{How does the marriage market clear? An empirical framework.}

(husband's) labor supply. We normalize the total amount of time for each individual to 1. Utilities from private and public consumption, and labor supplies are described by:

$$
U_{i j s}\left[C_{i j s}, 1-H_{i j s}, K_{i j s}\right]
$$

and

$$
u_{i j s}\left[c_{i j s}, 1-h_{i j s}, K_{i j s}\right]
$$

respectively. The felicity functions, $U_{i j s}($.$) and u_{i j s}($.$) , depend on i$ and $j$ to allow for differences in home production technologies across different types of marriages. If a woman chooses not to marry, then $i=0$ and if a man chooses not to marry, $j=0$.

Let $W_{i j s}$ be the wife's wage, $w_{i j s}$ be the husband's wage and $A_{i j s}$ be their joint non-labor or asset income. Here we are making a very strong assumption that all marriages of the same type, $\{i, j, s\}$, have the same wages and asset income. CSSa relaxes this strong assumption.

The hallmark of the collective model is that it assumes efficient allocation of intrahousehold resources. The efficient allocation can be posed as a social planner solving:

$$
\max _{\left\{C_{i j s}, c_{i j s}, H_{i j s}, h_{i j s}, K_{i j s}\right\}} U_{i j s}\left[C_{i j s}, 1-H_{i j s}, K_{i j s}\right]+\widetilde{p}_{i j s} u_{i j s}\left[c_{i j s}, 1-h_{i j s}, K_{i j s}\right]
$$

subject to the family budget constraint

$$
c_{i j s}+C_{i j s}+K_{i j s} \leq A_{i j s}+W_{i j s} H_{i j s}+w_{i j s} h_{i j s}
$$

In problem (P1), the planner chooses family consumption and labor supplies to maximize the weighted sum of the wife's and the husband's utilities subject to their family budget constraint. The weight allocated to the husband's utility is $\widetilde{p}_{i j s}, \widetilde{p}_{i j s} \in R^{+}$, where $\widetilde{p}_{i j s}>1$ 


\section{How does the marriage market clear? An empirical framework.}

implies the husband has more weight than the wife and vice versa. We will refer to $\widetilde{p}_{i j s}$ as

the husband's power. The social planner takes $\widetilde{p}_{i j s}$ as given when solving the intra-household allocation problem. The determination of $\widetilde{p}_{i j s}$ itself occurs in the marriage market.

Let $Q_{i j s}\left(\widetilde{p}_{i j s}, W_{i j s}, w_{i j s}, A_{i j s}\right)$ and $q_{i j s}\left(\widetilde{p}_{i j s}, W_{i j s}, w_{i j s}, A_{i j s}\right)$ be the indirect felicity functions of the wife and the husband, respectively. It is straightforward to show that:

Proposition 4 The changes in spousal utilities as the husband's power, $\widetilde{p}_{i j s}$, increases satisfy:

$$
\frac{\partial Q_{i j s}\left(\widetilde{p}_{i j s}, W_{i j s}, w_{i j s}, A_{i j s}\right)}{\partial \widetilde{p}_{i j s}}=-\widetilde{p}_{i j s} \frac{\partial q_{i j s}\left(\widetilde{p}_{i j s}, W_{i j s}, w_{i j s}, A_{i j s}\right)}{\partial \widetilde{p}_{i j s}}<0
$$

The wife's utility falls and the husband's utility increases as $\widetilde{p}_{i j s}$ increases. Equation (19) traces the redistribution of spousal utilities as the husband's power increases. We will now study how spousal labor supplies change as husband's power changes. Denote $H_{i j s}\left(\widetilde{p}_{i j s}, W_{i j s}, w_{i j s}, A_{i j s}\right)$ and $h_{i j s}\left(\widetilde{p}_{i j s}, W_{i j s}, w_{i j s}, A_{i j s}\right)$ as the labor supplies for the wife and husband that result from solving (P1). In general, it is difficult to determine analytically how spousal labor supplies respond to changes in $\widetilde{p}_{i j s}$. Building on Blundell et. al., CSSa shows that if the public good is weakly separable from private consumption and leisure, and if we restrict leisure (with suitably defined individual private income) and the public good to be normal goods for each spouse:

Proposition 5 The wife's labor supply is increasing in $\widetilde{p}_{i j s}$ whereas the husband's labor supply is decreasing in the husband's power, $\widetilde{p}_{i j s}$ :

$$
\begin{aligned}
& \frac{\partial H_{i j s}\left(\widetilde{p}_{i j s}, W_{i j s}, w_{i j s}, A_{i j s}\right)}{\partial \widetilde{p}_{i j s}}>0 \\
& \frac{\partial h_{i j s}\left(\widetilde{p}_{i j s}, W_{i j s}, w_{i j s}, A_{i j s}\right)}{\partial \widetilde{p}_{i j s}}<0
\end{aligned}
$$




\section{How does the marriage market clear? An empirical framework.}

\subsection{Marriage decisions and outcomes}

A woman can choose between $I$ types of men and $S$ type of living arrangements and also to remain unmarried (unattached). So she has $I \times S+1$ marital choices. Similarly, a man has $J \times S+1$ marital choices. For a particular woman of type $j$, her indirect utility from an $\{i, j, s\}$ marriage is:

$$
V_{i j s}\left(\widetilde{p}_{i j s}, W_{i j s}, w_{i j s}, A_{i j s}, \epsilon_{i j s}\right)=Q_{i j s}\left(\widetilde{p}_{i j s}, W_{i j s}, w_{i j s}, A_{i j s}\right)+\Gamma_{i j s}+\epsilon_{i j s}
$$

$\Gamma_{i j s}$ is every type $j$ woman's invariant gain from marrying a type $i$ man in living arrangement $s$. It is independent of $\tilde{p}_{i j s}, W_{i j s}, w_{i j s}, A_{i j s}$ and $\epsilon_{i j s} . \Gamma_{i j s}$ is used to fit the observed marriage matching distribution. $\epsilon_{i j s}$ is the particular woman's idiosyncratic payoff which is different for every woman. $\epsilon_{i j s}$ is an i.i.d. extreme value random variable. If the woman remains unmarried, denote her indirect utility as $V_{0 j}\left(W_{0 j}, A_{0 j}, \epsilon_{0 j}\right)=\Gamma_{0 j}+Q_{0 j}\left(W_{0 j}, A_{0 j}\right)+\epsilon_{0 j}$ where $\epsilon_{0 j}$ is an i.i.d. extreme value random variable.

Let her vector of idiosyncratic extreme values be $\epsilon_{j}$. The indirect utility from her optimal choice will satisfy:

$$
\begin{gathered}
V_{j}\left(\epsilon_{j}\right)=\max \left[V_{0 j}\left(W_{0 j}, A_{0 j}, \epsilon_{0 j}\right), ., V_{i j s}\left(\widetilde{p}_{i j s}, W_{i j s}, w_{i j s}, A_{i j s}, \epsilon_{i j s}\right), .,\right. \\
\left.V_{I j S}\left(p_{I j S}, W_{I j S}, w_{I j S}, A_{I j S}, \epsilon_{I j S}\right)\right]
\end{gathered}
$$

The indirect utility to a particular type $i$ man in an $\{i, j, s\}$ marriage is:

$$
v_{i j s}\left(\widetilde{p}_{i j s}, W_{i j s}, w_{i j s}, A_{i j s}, \varepsilon_{i j s}\right)=q_{i j s}\left(\widetilde{p}_{i j s}, W_{i j s}, w_{i j s}, A_{i j s} .\right)+\gamma_{i j s}+\varepsilon_{i j s}
$$

$\gamma_{i j s}$ is every type $i$ man's invariant gain from marrying a type $j$ woman in living arrangement $s$. It is independent of $\widetilde{p}_{i j s}, W_{i j s}, w_{i j s}, A_{i j s}$ and $\varepsilon_{i j s} . \gamma_{i j s}$ is used to fit the observed 


\section{How does the marriage market clear? An empirical framework.}

marriage matching distribution. $\varepsilon_{i j s}$ is the particular man's idiosyncratic payoff which is different for every man. $\varepsilon_{i j s}$ is an i.i.d. extreme value random variable. If the man remains unmarried, denote his indirect utility as $v_{i 0}\left(w_{i 0}, A_{i 0}, \varepsilon_{i 0}\right)=\gamma_{i 0}+q_{i 0}\left(w_{i 0}, A_{i 0}\right)+\varepsilon_{i 0}$ where $\varepsilon_{i 0}$ is an i.i.d. extreme value random variable.

The indirect utility from his optimal choice will satisfy:

$$
\begin{gathered}
v_{i}\left(\varepsilon_{i}\right)=\max \left[v_{i 0}\left(w_{i 0}, A_{i 0}, \varepsilon_{i 0}\right), ., v_{i j s}\left(\widetilde{p}_{i j s}, W_{i j s}, w_{i j s}, A_{i j s}, \varepsilon_{i j s}\right), .,\right. \\
\left.v_{i J}\left(p_{i J S}, W_{i J S}, w_{i J S}, A_{i J S}, \varepsilon_{i J S}\right)\right]
\end{gathered}
$$

As in CS, if there are many women of each type, the quasi demand of type $j$ women for $\{i, j, s\}$ marriages satisfies:

$$
\ln \bar{\mu}_{i j s}-\ln \bar{\mu}_{0 j}=\left(\Gamma_{i j s}-\Gamma_{0 j}\right)+Q_{i j s}\left(\widetilde{p}_{i j s}, W_{i j s}, w_{i j s}, A_{i j s}\right)-Q_{0 j}\left(W_{0 j}, A_{0 j}\right)
$$

where $\bar{\mu}_{i j s}$ is the number of $\{i, j, s\}$ marriages demanded by $j$ type females and $\bar{\mu}_{0 j}$ is the number of type $j$ females who choose to remain unmarried.

Similarly, for every type of man $i$, the quasi demand of type $i$ men for $\{i, j, s\}$ marriages is:

$$
\ln \underline{\mu}_{i j s}-\ln \underline{\mu}_{i 0}=\left(\gamma_{i j s}-\gamma_{i 0}\right)+q_{i j s}\left(\widetilde{p}_{i j s}, W_{i j s}, w_{i j s}, A_{i j s}\right)-q_{i 0}\left(w_{i 0}, A_{i 0}\right)
$$

where $\underline{\mu}_{i j s}$ is the number of $\{i, j, s\}$ marriages supplied by $j$ type males and $\underline{\mu}_{i 0}$ is the number of type $i$ males who choose to remain unmarried.

When the marriage market clears, $\bar{\mu}_{i j s}=\underline{\mu}_{i j s}=\mu_{i j s}$ for all $\{i, j, s\}$ sub-markets. In a more general setup, CSSa shows that:

Proposition 6 A market equilibrium exists. 


\section{How does the marriage market clear? An empirical framework.}

The sketch of the proof is as follows. Consider any $\{i, j, s\}$ sub marriage market. Holding all other $\widetilde{p}_{i^{\prime} j^{\prime} s^{\prime}}, i^{\prime} j^{\prime} s^{\prime} \neq i j s$, constant, as $\widetilde{p}_{i j s}$ increases, weakly more type $i$ men will enter into $\{i, j, s\}$ matches and weakly less of other types of matches. Weakly less type $j$ women will be willing to go into $\{i, j, s\}$ matches and weakly more into other types of matches. Thus the excess demand function for spouses in every $\{i, j, s\}$ submarriage market satisfies the weak gross substitute condition. A standard result from general equilibrium theory says that a marriage market equilibrium exists ( E.g. Mas-Colell, Winston and Green (1995: p. 646, exercise $\left.17 . \mathrm{F} .16^{C}\right)$ ).

Let $\widetilde{p}_{i j s}=p_{i j s}$ under market equilibrium. Imposing equilibrium, the male and female net gains equations respectively become:

$$
\begin{aligned}
& \ln \frac{\mu_{i j s}}{\mu_{i 0}}=\left(\gamma_{i j s}-\gamma_{i 0}\right)+q_{i j s}\left(p_{i j s}, W_{i j s}, w_{i j s}, A_{i j s}\right)-q_{i 0}\left(w_{i 0}, A_{i 0}\right) \\
& \ln \frac{\mu_{i j s}}{\mu_{0 j}}=\left(\Gamma_{i j s}-\Gamma_{0 j}\right)+Q_{i j s}\left(p_{i j s}, W_{i j s}, w_{i j s}, A_{i j s}\right)-Q_{0 j}\left(W_{0 j}, A_{0 j}\right)
\end{aligned}
$$

We add the net gains equations to get:

$$
\begin{aligned}
\ln \frac{\mu_{i j s}}{\sqrt{\mu_{i 0} \mu_{0 j}}} & =\frac{\left(\Gamma_{i j s}-\Gamma_{0 j}\right)+Q_{i j s}\left(p_{i j s}, W_{i j s}, w_{i j s}, A_{i j s}\right)-Q_{0 j}\left(W_{0 j}, A_{0 j}\right)}{2} \\
& +\frac{\left(\gamma_{i j s}-\gamma_{i 0}\right)+q_{i j s}\left(p_{i j s}, W_{i j s}, w_{i j s}, A_{i j s}\right)-q_{i 0}\left(w_{i 0}, A_{i 0}\right)}{2}
\end{aligned}
$$

The left hand side of (30) is the total gain to marriage which is the same as in (17). The right hand side of (30) depends on $p_{i j s}$, the husband's power, wages and asset incomes. $p_{i j s}$ is endogenous. Thus in general, total gain is not equal to only exogenous variables as in CS. 


\section{How does the marriage market clear? An empirical framework.}

\subsection{Market tightness, discrete and continuous spousal labor sup- ply decisions}

Subtracting male net gain, (28), from female net gain, 29), to get:

$$
\begin{aligned}
& T_{i j}=\ln \frac{\mu_{i 0}}{\mu_{0 j}}=\left(\Gamma_{i j s}-\Gamma_{0 j}\right)+Q_{i j s}\left(p_{i j s}, W_{i j s}, w_{i j s}, A_{i j s}\right)-Q_{0 j}\left(W_{0 j}, A_{0 j}\right) \\
& -\left(\left(\gamma_{i j s}-\gamma_{i 0}\right)+q_{i j s}\left(p_{i j s}, W_{i j s}, w_{i j s}, A_{i j s}\right)-q_{i 0}\left(w_{i 0}, A_{i 0}\right)\right)
\end{aligned}
$$

where $T_{i j}$ is marriage market tightness. Equation (31) is a generalization of (18). Unlike proposition 2 which is silent on the determinants of marital output, equation (31) says that important determinants of marital outputs include spousal wages and asset incomes. It is important to emphasize that $T_{i j}$ and $p_{i j s}$ are both endogenous variables and simultaneously determined. Thus equation (31) is not a statement about the causal effect of $T_{i j}$ on $p_{i j s}$.

To obtain a causal statement, consider a change in an exogenous parameter, $x$. Let $Z_{i j s}=\left[W_{i j s}, w_{i j s}, A_{i j s}, w_{i 0}, A_{i 0}, w_{0 j}, A_{0 j}\right]$. Using proposition 4 and (31)

$$
\begin{gathered}
\frac{\partial p_{i j s}}{\partial x}=\rho_{i j s} \frac{\partial \widehat{\Gamma}_{i j s}}{\partial x}+\rho_{i j s} \frac{\partial\left(\left(\mathbf{Q}_{i j s}-\mathbf{Q}_{0 j}\right)-\left(\mathbf{q}_{i j s}-\mathbf{q}_{i 0}\right)\right)}{\partial Z_{i j s}} \frac{\partial Z_{i j s}}{\partial x}-\rho_{i j s} \frac{\partial T_{i j}}{\partial x} \\
\widehat{\Gamma}_{i j s}=\left(\Gamma_{i j s}-\Gamma_{0 j}\right)-\left(\gamma_{i j s}-\gamma_{i 0}\right) ; \rho_{i j s} \equiv\left[\left(1+p_{i j s}\right) \frac{\partial \mathbf{q}_{i j s}}{\partial p_{i j s}}\right]^{-1}>0
\end{gathered}
$$

A change in $x$ induces three changes in the husband's power. The first is the effect of a change in relative spousal invariant gains, $\widehat{\Gamma}_{i j s}$, on power. The second term is proportional to the change in the difference in expected spousal utilities due to a change in $Z_{i j s}$ caused by a change in $x$. The third term is proportional to the change in marriage market tightness. Since $\rho_{i j s}>0$, when market tightness increases, the husband's power is predicted to fall. 


\section{How does the marriage market clear? An empirical framework.}

We can invert equation (31) to derive an expression for the husband's power:

$$
p_{i j s}=g_{i j s}\left(T_{i j}, \widehat{\Gamma}_{i j s}, Z_{i j s}\right)
$$

The empirical implication of equation (33) is as follows. Holding $\widehat{\Gamma}_{i j s}$ and $Z_{i j s}$ constant, if $T_{i j}$ stays the same, then $p_{i j s}$ stays the same and total gains in equation (30) stays the same. We now use equation (33) to derive empirical implications of our theory regarding the effect of marriage matching on spousal labor supplies. Recall that $H_{i j s}\left(p_{i j s}, W_{i j s}, w_{i j s}, A_{i j s}\right)$ is the hours of work of a wife of type $j$ in an $\{i, j, s\}$ marriage. Using proposition 5 , equation (32) and (33), the labor supply of a wife in an $\{i, j, s\}$ match is:

$$
\begin{aligned}
& H_{i j s}\left(T_{i j}, \widehat{\Gamma}_{i j s}, Z_{i j s}\right) \\
& \frac{\partial H_{i j s}}{\partial T_{i j}}<0
\end{aligned}
$$

That is, holding invariant gains to marriage and $Z_{i j s}$ constant, the wife's labor supply depends inversely on marriage market tightness. The exogenous variables that can change to affect tightness are the population vectors, $M$ and $F$ and determinants of marital surpluses from other marital matches that are uncorrelated with $\widehat{\Gamma}_{i j s}$ and $Z_{i j s}$.

Similarly, the labor supply of a husband in an $\{i, j, s\}$ match is:

$$
\begin{aligned}
& h_{i j s}\left(T_{i j}, \widehat{\Gamma}_{i j s}, Z_{i j s}\right) \\
& \frac{\partial h_{i j s}}{\partial T_{i j}}>0
\end{aligned}
$$

Holding relative invariant gains to marriage, wages and asset incomes from $\{i, j, s\}$ and unmarried matches constant, the husband's labor supply increases with marriage market tightness. 


\section{How does the marriage market clear? An empirical framework.}

Another use of market tightness is to consider two types of marital matches $\{i, j, s\}$ and $\left\{i, j, s^{\prime}\right\}$. For my application below, $s$ are marriages in which a spouse works and $s^{\prime}$ are marriages in which a spouse does not participate in the labor market. Using equation (31), market tightness is the same for both kinds of marital matches which implies:

$$
\begin{aligned}
& \Gamma_{i j s}+Q_{i j s}\left(p_{i j s}, W_{i j s}, w_{i j s}, A_{i j s}\right)-\gamma_{i j s}-q_{i j s}\left(p_{i j s}, W_{i j s}, w_{i j s}, A_{i j s}\right)=\Gamma_{i j s^{\prime}} \\
& +Q_{i j s^{\prime}}\left(p_{i j s^{\prime}}, W_{i j s^{\prime}}, w_{i j s^{\prime}}, A_{i j s^{\prime}}\right)-\gamma_{i j s^{\prime}}-q_{i j s^{\prime}}\left(p_{i j s^{\prime}}, W_{i j s^{\prime}}, w_{i j s^{\prime}}, A_{i j s^{\prime}}\right)
\end{aligned}
$$

Consider a change in population supplies, $x$. Holding $\widehat{\Gamma}_{i j s}$ and $Z_{i j s}$ constant, using equation (38) and proposition 4,

$$
\left(1+p_{i j s}\right) \frac{\partial q_{i j s}}{\partial p_{i j s}} \frac{\partial p_{i j s}}{\partial T_{i j}}=\left(1+p_{i j s^{\prime}}\right) \frac{\partial q_{i j s^{\prime}}}{\partial p_{i j s^{\prime}}} \frac{\partial p_{i j s^{\prime}}}{\partial T_{i j}}
$$

Equation (39) says that if the marginal utility of tightness is larger for living arrangement $s$ than $s^{\prime}$, then $p_{i j s}$ is smaller than $p_{i j s^{\prime}}$ and vice versa. So if one can compare marginal utilities of tightness between the two living arrangements, one can learn about their relative husband's powers.

To this end, use the male net gains equations for marital matches, $\{i, j, s\}$ and $\left\{i, j, s^{\prime}\right\}$ to get:

$$
\ln \frac{\mu_{i j s}}{\mu_{i j s^{\prime}}}=\gamma_{i j s}+q_{i j s}\left(p_{i j s}, W_{i j s}, w_{i j s}, A_{i j s}\right)-\gamma_{i j s^{\prime}}-q_{i j s^{\prime}}\left(p_{i j s^{\prime}}, W_{i j s^{\prime}}, w_{i j s^{\prime}}, A_{i j s^{\prime}}\right)
$$




\section{How does the marriage market clear? An empirical framework.}

Holding $\widehat{\Gamma}_{i j s}$ and $Z_{i j s}$ constant, equations (39) and (40) imply:

$$
\frac{\partial \ln \frac{\mu_{i j s}}{\mu_{i j s^{\prime}}}}{\partial T_{i j}}=-\left(\frac{p_{i j s}-p_{i j s^{\prime}}}{1+p_{i j s}}\right) \frac{\partial q_{i j s^{\prime}}}{\partial p_{i j s^{\prime}}} \frac{\partial p_{i j s^{\prime}}}{\partial T_{i j}}
$$

Since $\frac{\partial p_{i j s^{\prime}}}{\partial T_{i j}}<0$ and $\frac{\partial q_{i j s^{\prime}}}{\partial p_{i j s^{\prime}}}>0, \frac{\partial q_{i j s^{\prime}}}{\partial p_{i j s^{\prime}}} \frac{\partial p_{i j s^{\prime}}}{\partial x}<0$. Then:

Proposition 7 Holding $\widehat{\Gamma}_{i j s}$ and $Z_{i j s}$ constant,

$$
\operatorname{sign}\left(\partial \ln \frac{\mu_{i j s}}{\mu_{i j s^{\prime}}} / \partial T_{i j}\right)=\operatorname{sign}\left(p_{i j s}-p_{i j s^{\prime}}\right)
$$

In words, holding $\widehat{\Gamma}_{i j s}$ and $Z_{i j s}$ constant, if the share of $s$ living arrangements increases relative to that of $s^{\prime}$ living arrangements as tightness increases, the husband's power in $s$ living arrangements exceeds that in $s^{\prime}$ living arrangements. We will apply the above proposition to interpret how the log odds of spouses participating in the labor market respond to variations in tightness.

Finally, there is the equivalent of proposition 3 :

Proposition 8 For every $\{i, j, s\}$, the net gains equations, (28) and (29), imply (30) and (31), and vice versa.

\section{$5 \quad$ Estimation and testing strategies}

We have not yet attempted to estimate all the parameters of the collective marriage matching model, partly because we have not yet established what is needed for identification, and partly because there are so many more parameters to estimate. Although the collective marriage matching model is a general equilibrium model, it admits decentralized estimation and testing strategies as is usual for competitive equilibrium models. For any marital match, $\{i, j, s\}$, the wives' and husbands' labor supply functions are respectively:

$$
H_{i j s}\left(p_{i j s}, W_{i j s}, w_{i j s}, A_{i j s}\right) \& h_{i j s}\left(p_{i j s}, W_{i j s}, w_{i j s}, A_{i j s}\right)
$$




\section{How does the marriage market clear? An empirical framework.}

These functions only depend on exogenous parameters specific to the $\{i, j, s\}$ match, $W_{i j s}$,

$w_{i j s}, A_{i j s}$, and an endogenous parameter, husband's power, $p_{i j s}$, which is also specific to the match. $p_{i j s}$ encapsulates all general equilibrium concerns. Thus if we can find determinants or proxies for $p_{i j s}$ which are unrelated to $W_{i j s}, w_{i j s}$ and $A_{i j s}$, we can estimate the subset of labor supply functions for we have empirical specifications for the labor supply functions and the necessary data. These parameter estimates will be consistent even though we ignore other marital matches where we do not have data and/or empirical specifications for the labor supply functions.

A similar decentralization result holds for estimating the marital matching equations, total gains and marriage market tightness equations, (30) and (31), or equivalently net gains equations (28) and (29). For any $\{i, j, s\}$ match, in addition to $W_{i j s}, w_{i j s}, A_{i j s}$, and $p_{i j s}$, we also need $W_{0 j}, A_{0 j}, w_{i 0}$ and $A_{i 0}$. If we have empirical proxies for these variables and empirical specifications for the marital matching equations for a subset of marital matches, we can estimate the marital matching equations for that subset.

\subsection{Empirical evidence using market tightness}

CSSa estimates the effect of changes in marriage market tightness on spousal labor supplies using the 2000 US census. Define an individual's type as a combination of race, age and education. For each gender, there are four contiguous age categories of 5 years each. The ages are staggered by two years across gender to reflect the fact that most men marry younger women. The youngest female and male age categories are 25-29 and 27-31 respectively. For each gender, there are two schooling categories: high school graduates (at least 12 and up 


\section{How does the marriage market clear? An empirical framework.}

to and including 15 years of education) and college graduates (16 years of education and

higher). Thus for each race and gender, there are 8 potential types of individuals. Since we are only considering same race marriages, whites, blacks and hispanics, there are potentially $64 \times 3=192$ types of marital matches for each society.

We treat each state $\mathfrak{s}$ as a separate isolated society. With 50 states, there are potentially $192 \times 50=9600$ cells across all sub-marriage markets. However, the majority of these potential cells (marital match $\{i, j\} \times$ state $\{\mathfrak{s}\}$ ) have few or no marriages. To avoid thin cell problems, we delete a cell if the number of marriages in that cell is less than 5. For most regressions, we have about 2400 observations. Most of the missing cells are due to non-white marriages, with large spousal age differences, in states with small populations. We also exclude mixed race couples to mitigate thin cells. ${ }^{13}$ Excluding thin cells from the empirical analysis should not affect the consistency of my estimates. As discussed above, my labor supplies regressions have to hold for any subset of marital matches.

In CSSa and the sample here, an observation is a cell. Mean $T_{i j}$ is -0.129 with a standard deviation of 0.962. About half the cells involve white marriages and the rest are black and hispanic marriages. ${ }^{14}$ Mean ages by cell are between 35-39 for women and 37-41 for men. For both genders, there are slightly more high school graduates than college graduates. To control for aggregate labor market conditions in an individual's local marriage market, we define the following three variables to characterize the earnings and asset income distributions. First, conditional on positive annual labor earnings for a type of unmarried individual, we construct the mean and standard deviation of log annual labor earnings for the distribution 


\section{How does the marriage market clear? An empirical framework.}

of unmarried individuals (wage and salary income). The second measure is the fraction of individuals with zero labor earnings for each match type in each marriage market. Finally, we construct the analogous variables for asset earnings, defined from the Census as total personal income minus wage and salary income. ${ }^{15}$ Note that we do not include marital wages and asset incomes. In other words, we am using unmarried wages and asset income proxies as control functions for the wages and asset income for both married and unmarried individuals.

The labor force participation rates for husbands and wives are $94 \%$ and $73 \%$, respectively. We consider two measures of labor supply. ${ }^{16}$ My first measure is the log odds of LFP (labor force participation). Conditional on participating in the labor force, my second measure of labor supply is the log of usual hours worked per week. Mean usual hours worked for men and women were 45 and 34 hours respectively.

CSSa shows that after controlling for own sex ratios, variations in substitutes' sex ratios also affect spousal labor supplies. ${ }^{17}$ With many different sex ratios in the labor supply regressions and the associated problem of multicollinearity, tightness provides a convenient summary statistic for marriage market conditions. An advantage to using $T_{i j}$ in spousal labor supply regressions, rather than sex ratios, is that the estimated coefficient has a clear behavioral interpretation. It alerts us to the conclusion that a labor supply regression with labor market controls and only the own sex ratio as a proxy for marriage market conditions has no clear causal interpretation.

Since tightness is endogenous, we instrument tightness by the population vectors in each 


\section{How does the marriage market clear? An empirical framework.}

state (by age and race and average educational attainment of their parents) twenty years earlier.

Table 1 shows the estimated effect of market tightness on the log odds of labor force participation (LFP) of wives and husbands. All regressions include state effects. These state effects control for state differences in labor market conditions as well as differences in state level invariant gains. Other controls include labor market and asset income controls at the individual type and state level, and individual type effects. We interpret the labor force participation status of a spouse as a living arrangement. In other words, marriages in which the wife works are one living arrangement and marriages in which the wife does not work are another living arrangement. Under this interpretation, the estimates of the coefficient

on tightness in Table 1 provide estimates of $\partial \ln \frac{\mu_{i j s}}{\mu_{i j s^{\prime}}} / \partial T_{i j}$ in equation (41) where $s$ denotes marriages with a working wife and $s^{\prime}$ those who do not.

Columns (1) to (3) are estimates for wives. $T_{i j}$ is affected by variations in invariant gains and labor market conditions. We control for these variations with state and individual effects. There are variations in invariant gains that we do not control for. Instrumenting $T_{i j}$ with sex ratios at birth should mitigate the endogeneity problem. The point estimate of 0.330 in column (1), which only includes state effects as the other covariates, shows that instrumenting $T_{i j}$ is not sufficient to obtain the "right" estimated sign. Column (2) adds labor market conditions. In this case, the estimated coefficient on $T_{i j}$ is -0.176 and it is statistically different from zero. Column (3) adds labor market conditions and individual effects. The point estimate on $T_{i j}$ is -0.167 and the standard error is 0.065 . So the point 


\section{How does the marriage market clear? An empirical framework.}

estimate is similar to that without individual effects but the standard error doubles.

Using the point estimate of -0.176 in column (2) as a benchmark, a one standard deviation increase in $T_{i j}$ will decrease the log odds LFP of wives by 0.26 standard deviation. Thus variation in tightness is quantitatively important for explaining variations in the log odds LFP of wives across matches and/or societies. Ceteris paribus, women and men are more willing to enter into marriages where the wife does not work when $T_{i j}$ increases. Equation (41) and the signs of our estimates also imply that husband's power is lower in marriages in which the wife works than in marriages in which she does not.

Columns (4) to (6) are estimates for husbands. The point estimate of $T_{i j}$ is -0.034 in column (4) which only includes state effects. Column (5) adds labor market conditions. In this case, the estimated coefficient on $T_{i j}$ is 0.145 and it is statistically different from zero at the $1 \%$ level. Column (6) adds labor market conditions and individual effects. The point estimate on $T_{i j}$ is 0.015 and the standard error is 0.072 . The point estimate is smaller than in column (5) and the standard error is significantly larger. This fall in estimated precision is the same for the other specifications.

Using the point estimate of 0.145 in column (5) as a benchmark, a one standard deviation increase in $T_{i j}$ will decrease the log odds LFP of husbands by 0.16 standard deviation. Thus variation in tightness has a smaller standardized impact on the log odds LFP of husbands than wives. This smaller impact by standard deviation is driven by the larger standard deviation in log LFP of husbands across cells. Equation (41) and the signs of our estimates also imply that husband's power is higher for husbands who work than those who do not. 


\section{How does the marriage market clear? An empirical framework.}

[Insert Table 1 and 2 here]

The estimates in Table 1 show that changing marriage market conditions substantially affect spousal LFP. These results are comparable to that found in the literature on the response of female LFP to changes in labor market conditions. Since estimates of LFP equations are standard in the labor literature, it is useful that the collective marriage matching model rationalizes these LFP equations in the context of the collective model. ${ }^{18}$

Table 2 columns (1) to (3) show the estimated effects of market tightness on the log usual hours of work per week of working wives. Column (1) adds state effects. The point estimate on $T_{i j}$ has the wrong sign and is statistically different from zero at the $5 \%$ level. Column (2) adds state effects and labor market conditions. The point estimate on $T_{i j}$ is -0.028 and the estimated standard error is 0.005. Column (6) adds state effects, labor market conditions and individual effects. The point estimate on $T_{i j}$ is -0.044 and the standard error is 0.010 . Thus adding individual effects lowers the estimated precision on $T_{i j}$. The estimates in Table 2 is qualitatively similar to their counterparts in Table 1 . The estimated magnitudes on $\ln$ hrs/wk are smaller than for participation. Using the estimate in column (2) as a benchmark, a one standard deviation increase in $T_{i j}$ results in 0.065 standard deviation decrease in $\ln$ hrs/wk for wives. So variation in tightness explains less of the variation in mean log usual hours of work per week of wives compared with log odds of LFP.

Columns (4) to (6) are estimates for husbands. As before, state effects alone in Column (4) results in a estimate that is statistically not different from zero. Column (5) adds state effects and labor market conditions. The point estimate on $T_{i j}$ is 0.018 and the estimated 


\section{How does the marriage market clear? An empirical framework.}

standard error is 0.003. Column (6) adds state effects, labor market conditions, individual effects. The point estimate on $T_{i j}$ is not statistically different from zero at the $5 \%$ level. Thus adding individual effects lower the estimated precision on $T_{i j}$. The estimated elasticities on hrs/wk are smaller than for participation. Using the estimate in column (5) as a benchmark, a one standard deviation increase in $T_{i j}$ results in 0.068 standard deviation increase in $\ln$ hrs/wk for husbands. So variation in tightness explains less of the variation in mean log usual hours of work per week of husbands than of log odds LFP.

The empirical results discussed add to the literature on the estimated effects of changes in marriage market conditions on spousal labor supplies. The estimates are qualitatively consistent with both theory and the evidence in the literature. As already noticed in the literature, it is important to control for labor market conditions. Otherwise, the point estimates of the effects of $T_{i j}$ on spousal labor supplies consistently have the wrong sign. The fact that variation in tightness affect labor force participation to a greater degree than they affect hours of work per week is consistent with the finding in the literature that participation is more sensitive than hours of work to determinants of labor supplies. Finally, we find theoretically consistent estimated effects for male labor supplies, which is uncommon for this literature.

A caveat is important. The empirical evidence also shows that market tightness is not always a sufficient statistic for own and substitute sex ratios. That is, in some spousal labor supply regressions which include market tightness as an endogenous regressor, we cannot reject the hypothesis that own and substitute sex ratios also affect spousal labor supplies. 


\section{How does the marriage market clear? An empirical framework.}

There are two non-mutually exclusive reasons for this finding. First, the instruments may not be valid. ${ }^{19}$ Second, the logit specification of spousal choice may be too restrictive. ${ }^{20}$

At this stage, our interpretation of the empirical results is that market tightness is a first order approximation for marriage market conditions and not a sufficient statistic.

\subsection{Do spousal labor supplies clear the marriage market?}

While the previous empirical results and the results in the literature on the estimated effects of changes in sex ratios on spousal labor supplies show that changes in marriage market conditions affect spousal labor supplies, we do not know whether the estimated effects are large enough to clear the marriage market. One cannot address this question unless we estimate a structural model of marriage market clearing and spousal labor supplies.

CSSb does this for a particular set of marriages. Using the model in the previous section, consider the set of marriages $\{i, j, s\}$ in which both spouses work and there is no public goods consumption. For convenience, we will also dispense with the $s$ subscript. In this case, CSSb shows that the intra-household allocation model is the same as that in CFL. CFL showed that the wife's and husband's labor supplies are:

$$
\begin{aligned}
& \left.H_{i j}\left(p_{i j}, W_{i j}, w_{i j}, A_{i j}\right)=\tilde{H}_{i j}\left[W_{i j}, \tau_{i j}\left(p_{i j}\right)\right)\right] \\
& h_{i j}\left(p_{i j}, W_{i j}, w_{i j}, A_{i j}\right)=\tilde{h}_{i j}\left[w_{i j}, A_{i j}-\tau_{i j}\left(p_{i j}\right)\right]
\end{aligned}
$$

where $\widetilde{H}_{i j}$ and $\widetilde{h}_{i j}$ are standard Marshallian labor supply functions with $\tau_{i j}\left(p_{i j}\right)$ and $A_{i j}-\tau_{i j}\left(p_{i j}\right)$ being asset incomes for the wife and husband respectively. Let husband's 


\section{How does the marriage market clear? An empirical framework.}

power, $p_{i j}$, be a function of $R_{i j}, W_{i j}, w_{i j}, A_{i j}$ where $R_{i j}$ is a vector of other factors which affect husband's power. When we hold invariant gains to marriage, wages and asset incomes constant, $R_{i j}$ consists of population vectors, $M$ and $F$, and determinants of marital surpluses from other marital matches including remaining unmarried. ${ }^{21}$

Let $r_{i j}$ be an element of $R_{i j}$. Dropping the $i j$ subscript for convenience, define $B_{1}=\frac{h_{W}}{h_{A}}$, $D_{1}=\frac{h_{r}}{h_{A}}, E_{1}=\frac{H_{w}}{H_{A}}$, and $F_{1}=\frac{H_{r}}{H_{A}}$. CFL shows:

Proposition 9 The partial derivatives of $\tau(p)$ are given by:

$$
\begin{aligned}
\tau_{p} p_{A} & =\frac{D_{1}}{D_{1}-F_{1}} \\
\tau_{p} p_{r} & =\frac{D_{1} F_{1}}{D_{1}-F_{1}} \\
\tau_{p} p_{W} & =\frac{B_{1} F_{1}}{D_{1}-F_{1}} \\
\tau_{p} p_{w} & =\frac{D_{1} E_{1}}{D_{1}-F_{1}}
\end{aligned}
$$

CSSb shows that in the marriage market, the equilibrium quasi demand of type $j$ women for $\{i, j, s\}$ marriages satisfy:

$$
\ln \frac{\mu_{i j}}{\mu_{0 j}}=\left(\Gamma_{i j}-\Gamma_{0 j}\right)+Q\left(W_{i j}, \tau_{i j}\left(p_{i j}\right)\right)-Q_{0 j}\left(W_{0 j}, A_{0 j}\right)
$$

Similarly, for every type of man $i$, the equilibrium quasi demand for $\{i, j, s\}$ marriages is:

$$
\ln \frac{\mu_{i j}}{\mu_{i 0}}=\left(\gamma_{i j}-\gamma_{i 0}\right)+q_{i j}\left(w_{i j}, A_{i j}-\tau_{i j}\left(p_{i j}\right)\right)-q_{i 0}\left(w_{i 0}, A_{i 0}\right)
$$

Denote the net gains by $N_{i j}=\ln \frac{\mu_{i j}}{\mu_{0 j}}$ and $n_{i j}=\ln \frac{\mu_{i j}}{\mu_{i 0}} . N_{i j}$ and $n_{i j}$ are observable by the researcher. Then the net gains reduced forms $N_{i j}$ and $n_{i j}$ satisfy: 


\section{How does the marriage market clear? An empirical framework.}

$$
\begin{aligned}
& N_{i j}\left(W_{i j}, w_{i j}, A_{i j}, w_{i 0}, A_{i 0}, W_{0 j}, A_{0 j}, R_{i j}\right)=\left(\Gamma_{i j}-\Gamma_{0 j}\right)+Q\left(W_{i j}, \tau_{i j}\left(p_{i j}\right)\right)-Q_{0 j}\left(W_{0 j}, A_{0 j}\right) \\
& n_{i j}\left(W_{i j}, w_{i j}, A_{i j}, w_{i 0}, A_{i 0}, W_{0 j}, A_{0 j}, R_{i j}\right)=\left(\gamma_{i j}-\gamma_{i 0}\right)+q_{i j}\left(w_{i j}, A_{i j}-\tau_{i j}\left(p_{i j}\right)\right)-q_{i 0}\left(w_{i 0}, A_{i 0}\right)
\end{aligned}
$$

Dropping the $i j$ subscript for convenience, define $B_{2}=\frac{N_{r}}{N_{A}}, D_{2}=\frac{n_{W}}{n_{A}}, E_{2}=\frac{N_{w}}{N_{A}}$, and $F_{2}=\frac{n_{r}}{n_{A}}$

CSSb shows that:

Proposition 10 The partial derivatives of $\tau(p)$ are given by:

$$
\begin{aligned}
\tau_{p} p_{A} & =\frac{F_{2}}{F_{2}-B_{2}} \\
\tau_{p} p_{r} & =\frac{B_{2} F_{2}}{F_{2}-B_{2}} \\
\tau_{p} p_{W} & =\frac{B_{2} D_{2}}{F_{2}-B_{2}} \\
\tau_{p} p_{w} & =\frac{E_{2} F_{2}}{F_{2}-B_{2}}
\end{aligned}
$$

Propositions 9 and 10 provide us with the following set of over-identifying restrictions:

\section{Proposition 11}

$$
\begin{aligned}
\tau_{p} p_{A} & =\frac{D_{1}}{D_{1}-F_{1}}=\frac{F_{2}}{F_{2}-B_{2}} \\
\tau_{p} p_{r} & =\frac{D_{1} F_{1}}{D_{1}-F_{1}}=\frac{B_{2} F_{2}}{F_{2}-B_{2}} \\
\tau_{p} p_{W} & =\frac{B_{1} F_{1}}{D_{1}-F_{1}}=\frac{B_{2} D_{2}}{F_{2}-B_{2}} \\
\tau_{p} p_{w} & =\frac{D_{1} E_{1}}{D_{1}-F_{1}}=\frac{E_{2} F_{2}}{F_{2}-B_{2}}
\end{aligned}
$$

Something like Proposition 11 should be expected. The CS class of marriage matching models assumes that individuals make their marital choices based on comparing their indirect utilities from different choices. These indirect utilities depend on private consumption, public 


\section{How does the marriage market clear? An empirical framework.}

consumption and own labor supplies. Thus we should expect net gains to depend on the determinants of husband's power as well as own wages and asset incomes. What proposition 11 says is that since we can identify the determinants of husband's power using spousal labor supplies as per proposition 9, and by using net gains as per proposition 10, these two different ways of estimating these determinants should give the same results.

If one spouse does not work, there is only one spousal labor supply equation and the identification of the determinants of husband's power fails. CSSb shows that the determinants of husband's power continue to be identified by estimating the two net gains equations when one spouse does not work.

An important contribution of CSSb is to include $W_{0 j}, w_{i 0}, A_{0 j}$, and $A_{i 0}$ in the $R_{i j}$ vector. That is, we include the opportunity costs of entering into the $\{i, j\}$ marriage in $R_{i j}$. Using the data from the 2000 US census, our preliminary empirical results largely show that when an individual's cost, i.e. $W_{0 j}, w_{i 0}, A_{0 j}$, or $A_{i 0}$, of entering the marriage increases, his or her spouse's labor supply increases. Generally, the estimated effects of exogenous variables on husband's power using net gains are more consistent with the theory than from those using spousal labor supplies. Finally, we cannot reject proposition 11 albeit the estimated standard errors are large.

\section{A lifecycle CS model}

This section presents an earlier version of Choo Siow (2007), a two period lifecycle CS model with no divorce and time varying supplies of new entrants. The objective of this section is 


\section{How does the marriage market clear? An empirical framework.}

to show that the CS framework extends naturally to lifecycle considerations.

Every adult lives for two periods, one and two. The age of a male is indexed by $i$ and the age of a female is indexed by $j$. In any period (year), the type of an adult is defined by his or her age. We may also call age one adults young and age two adults old. There is no divorce. An adult whose spouse dies will automatically return to the marriage market in the next period. For analytic convenience, widowed individuals and never married individuals of the same age and gender are the same in the marriage market.

Let $\left\{m_{1}^{t}, f_{1}^{t}\right\}$ be the number of young males and females who enter the society at year $t$. Let $\mu_{i j}^{t}$ be the number of age $i$ males who marry age $j$ females at year $t$. Without divorce, we have the following accounting identities:

$$
\begin{gathered}
m_{2}^{t+1}=m_{1}^{t}-\mu_{11}^{t} \\
f_{2}^{t+1}=f_{1}^{t}-\mu_{11}^{t}
\end{gathered}
$$

For convenience, the discount factor is set to one. Let $\pi_{i j}^{t}$ be the discounted within marriage payoffs where an age $i$ male marries an age $j$ female in year $t$. This is the discounted within marriage payoff which is divided between the two spouses. Let $v_{i}^{t}$ be the expected discounted payoff to a type $i$ male of being available in the marriage market in year $t$. When a type $i$ male marries a type $j$ female in year $t, r_{i j}^{t}$ is his expected discounted marriage termination payoffs. It is defined as:

$$
r_{i j}^{t}=\delta_{i j} v_{2}^{t+1}
$$

where $\delta_{12}=1$, and $\delta_{11}=\delta_{2 j}=0$. 


\section{How does the marriage market clear? An empirical framework.}

When an $\{i, j\}$ couple marry, not all within marital payoff accrues to the husband. Let $\tau_{i j}^{t}$ be the equilibrium share of the within marriage output of an $\{i, j\}$ marriage in year $t$ that accrues to the wife. The systematic expected discounted payoff to a type $i$ male who enters into a marriage with a type $j$ female in year $t$ consists of his systematic expected discounted within marriage payoff, $\pi_{i j}^{t}-\tau_{i j}^{t}$, and his expected discounted marriage termination payoff, $r_{i j}^{t}$ :

$$
\pi_{i j}^{t}-\tau_{i j}^{t}+r_{i j}^{t}
$$

A particular type $i$ male, $g$, who chooses to marry a type $j$ female in year $t$ will receive an expected discounted payoff of:

$$
v_{i j g}^{t}=\pi_{i j}^{t}-\tau_{i j}^{t}+r_{i j}^{t}+\varepsilon_{i j g}^{t}
$$

$\varepsilon_{i j g}^{t}$ is the realization of an i.i.d. random variable with type I extreme value distribution.

Thus his expected discounted payoff, $v_{i j g}^{t}$, consists of two components, a systematic discounted payoff (which is common to all such marriages) and an idiosyncratic payoff which applies only to him. If he chooses not to marry, his expected discounted payoff is:

$$
v_{i 0 g}^{t}=\pi_{i 0}^{t}+r_{i 0}^{t}+\varepsilon_{i 0 g}^{t}
$$

The systematic expected discounted payoff from not marrying at age $i$ consists of two components, a current payoff $\pi_{i 0}^{t}$ and an expected discounted payoff from being in the marriage market again in the next period, $r_{i 0}^{t}=\delta_{i 0} v_{2}^{t}$ where $\delta_{10}=1$ and $\delta_{20}=0$. $\varepsilon_{i 0 g}^{t}$ is the realization of an i.i.d. random variable with type I extreme value distribution. 


\section{How does the marriage market clear? An empirical framework.}

The objective of male $g$ in year $t$ is to choose whether to remain unmarried or whom to marry in order to maximize his discounted utility:

$$
\begin{aligned}
v_{i g}^{t} & =\max \left\{v_{i 1 g}^{t}, v_{i 2 g}^{t}, v_{i 0 g}^{t}\right\} \\
& =\max \left\{\pi_{i 1}^{t}-\tau_{i 1}^{t}+r_{i 1}^{t}+\varepsilon_{i 1 g}^{t}, \pi_{i 2}^{t}-\tau_{i 2}^{t}+r_{i 2}^{t}+\varepsilon_{i 2 g}^{t}, \pi_{i 0}^{t}+r_{i 0}^{t}+\varepsilon_{i 0 g}^{t}\right\}
\end{aligned}
$$

Assume that the numbers of men and women of each type is large. Let $\underline{\mu}_{i j}^{t}$ be the number of type $i$ males who want to marry type $j$ females in year $t$. Let $\underline{\mu}_{i 0}^{t}$ be the number of type $i$ males who want to remain unmarried in year $t$. Then the quasi-demand equation by type $i$ males to marry type $j$ females is:

$$
\ln \underline{\mu}_{i j}^{t}-\ln \underline{\mu}_{i 0}^{t}=\pi_{i j}^{t}-\tau_{i j}^{t}+r_{i j}^{t}-\pi_{i 0}-r_{i 0}^{t}, j=1,2
$$

The following standard results also obtain (E.g. CS):

$$
\begin{gathered}
v_{i}^{t}-v_{i 0}^{t}=\ln \left[\frac{m_{i}^{t}}{\underline{\mu}_{i 0}^{t}}\right] \\
v_{i 0}^{t}=c+\pi_{i 0}^{t}
\end{gathered}
$$

Turning to the equivalent equations to Equation (50) for women, let $V_{j}^{t}$ be the expected discounted payoff to a type $j$ female of being available in the marriage market in year $t$. Recall that if she marries a type $i$ male in year $t$, she will receive a within marriage output of $\tau_{i j}^{t}$. Let $R_{i j}^{t}$ denote her expected discounted end of marriage payoff. $R_{i j}^{t}$ is defined by:

$$
R_{i j}^{t}=\phi_{i j} V_{2}^{t+1}
$$




\section{How does the marriage market clear? An empirical framework.}

where $\phi_{21}=1$ and $\phi_{11}=\phi_{i 2}=0$. So the systematic expected discounted payoff to a type $j$ female who enters into a marriage in year $t$ with a type $i$ male is:

$$
\tau_{i j}^{t}+R_{i j}^{t}
$$

Female utilities from marriage are modelled similarly to those of the males. A particular type $j$ female, $k$, who chooses to marry a type $i$ male in year $t$ will receive an expected discounted payoff of:

$$
V_{i j k}^{t}=\tau_{i j}^{t}+R_{i j}^{t}+\epsilon_{i j k}^{t}
$$

$\epsilon_{i j k}^{t}$ is the realization of an i.i.d. random variable with type I extreme value distribution. If she chooses not to marry, her expected discounted payoff is:

$$
V_{0 j k}^{t}=\pi_{0 j}^{t}+R_{0 j}^{t}+\epsilon_{0 j k}^{t}
$$

Her systematic expected discounted payoff from not marrying at age $j$ consists of two components, a current payoff $\pi_{0 j}^{t}$ and an expected discounted payoff from being in the marriage market again in the next period, $R_{0 j}^{t}=\phi_{0 j} V_{2}^{t+1}$ where $\phi_{01}=1$ and $\phi_{02}=0$. $\epsilon_{0 j k}^{t}$ is the realization of an i.i.d. random variable with type I extreme value distribution. The objective of female $k$ in year $t$ is to choose whether to remain unmarried or whom to marry in order to maximize her expected discounted utility:

$$
V_{j k}^{t}=\max \left\{V_{0 j k}^{t}, V_{1 j k}^{t}, V_{2 j k}^{t}\right\}
$$

Let $\bar{\mu}_{i j}^{t}$ be the number of type $j$ females who want to marry type $i$ males in year $t$. Let 
How does the marriage market clear? An empirical framework.

$\bar{\mu}_{0 j}^{t}$ be the number of type $j$ females in year $t$ who want to remain unmarried. Then

$$
\begin{aligned}
\ln \underline{\mu}_{i j}^{t}-\ln \underline{\mu}_{0 j}^{t} & =\tau_{i j}^{t}+R_{i j}^{t}-\pi_{0 j}^{t}-R_{0 j}^{t}, i=1,2 \\
V_{j}^{t}-V_{j 0}^{t} & =\ln \left[\frac{f_{j}^{t}}{\bar{\mu}_{0 j}^{t}}\right] \\
V_{j 0}^{t} & =c+\pi_{0 j}^{t}
\end{aligned}
$$

\subsection{Marriage market clearing}

In each year $t$, there are 4 submarriage markets, $\{i, j\}=\{1,1\},\{1,2\},\{2,1\},\{2,2\}$. The marriage market clears when all submarriage markets in the current and future years clear. Assuming that the marriage market clears, given equilibrium shares, $\tau_{i j}^{t} \forall\{i, j\}$, the demand for spouses by males is equal to the supply of spouses by females for every submarket. So the equilibrium number of $\{i, j\}$ marriages, $\mu_{i j}^{t}$, satisfies:

$$
\mu_{i j}^{t}=\underline{\mu}_{i j}^{t}=\bar{\mu}_{i j}^{t}
$$

From (57) and (50), the definitions of $r_{i j}^{t}$ and (51)

$$
\begin{aligned}
\ln \mu_{i j}^{t}-\ln \mu_{i 0}^{t} & =\pi_{i j}^{t}-\tau_{i j}^{t}+r_{i j}^{t}-\pi_{i 0}^{t}-r_{i 0}^{t} \\
& =\pi_{i j}^{t}-\tau_{i j}^{t}-\pi_{i 0}^{t}+\left(\delta_{i j}-\delta_{i 0}\right)\left(c+\pi_{20}^{t}+\ln \left[\frac{m_{2}^{t+1}}{\mu_{20}^{t+1}}\right]\right)
\end{aligned}
$$

Similarly,

$$
\begin{aligned}
\ln \mu_{i j}^{t}-\ln \mu_{0 j}^{t} & =\tau_{i j}^{t}+R_{i j}^{t}-\pi_{0 j}^{t}-R_{0 j}^{t} \\
& =\tau_{i j}^{t}-\pi_{0 j}^{t}+\left(\phi_{i j}-\phi_{0 j}\right)\left(c+\pi_{02}^{t}+\ln \left[\frac{f_{2}^{t+1}}{\mu_{02}^{t+1}}\right]\right)
\end{aligned}
$$


How does the marriage market clear? An empirical framework.

Add (58) and (60) to obtain:

$$
\begin{aligned}
\ln \left[\frac{\mu_{i j}^{t}}{\sqrt{\mu_{0 j}^{t} \mu_{i 0}^{t}}}\right] & =\frac{\pi_{i j}^{t}-\left(\pi_{i 0}^{t}+\pi_{0 j}^{t}\right)}{2}+\frac{r_{i j}^{t}-r_{i 0}^{t}+R_{i j}^{t}-R_{0 j}^{t}}{2} \\
& =\Gamma_{i j}^{t}-\Delta_{i j}^{t}
\end{aligned}
$$

where

$$
\begin{aligned}
\Gamma_{i j}^{t} & =\frac{\pi_{i j}^{t}-\left(\pi_{i 0}^{t}+\pi_{0 j}^{t}\right)}{2}+\frac{\left(\delta_{i j}-\delta_{i 0}\right)}{2}\left(c+\pi_{20}^{t}\right)+\frac{\left(\phi_{i j}-\phi_{0 j}\right)}{2}\left(c+\pi_{02}^{t}\right) \\
\Delta_{i j}^{t} & =\frac{\left(\delta_{i 0}-\delta_{i j}\right)}{2} \ln \left[\frac{m_{2}^{t+1}}{\mu_{20}^{t+1}}\right]+\frac{\left(\phi_{0 j}-\phi_{i j}\right)}{2} \ln \left[\frac{f_{2}^{t+1}}{\mu_{02}^{t+1}}\right]
\end{aligned}
$$

$\Gamma_{i j}^{t}$ does not depend on demand and supply conditions, $m_{1}^{t^{\prime}}$ or $f_{1}^{t^{\prime}}$ for any $t^{\prime}$. Using (62) and (64), we get:

$$
\Gamma_{i j}^{t}=\ln \left[\frac{\mu_{i j}^{t}}{\sqrt{\mu_{i 0}^{t} \mu_{0 j}^{t}}}\right]+\frac{\left(\delta_{i 0}-\delta_{i j}\right)}{2} \ln \left[\frac{m_{2}^{t+1}}{\mu_{20}^{t+1}}\right]+\frac{\left(\phi_{0 j}-\phi_{i j}\right)}{2} \ln \left[\frac{f_{2}^{t+1}}{\mu_{02}^{t+1}}\right]
$$

If marital outputs are year invariant, $\Gamma_{i j}^{t}=\Gamma_{i j}$, which is independent of $t$. Then (66) imposes very strong restriction on the data. It says that: 
How does the marriage market clear? An empirical framework.

$$
\begin{aligned}
& \ln \left[\frac{\mu_{11}^{t}}{\sqrt{\mu_{10}^{t} \mu_{01}^{t}}}\right]+\frac{1}{2} \ln \left[\frac{m_{2}^{t+1}}{\mu_{20}^{t+1}}\right]+\frac{1}{2} \ln \left[\frac{f_{2}^{t+1}}{\mu_{02}^{t+1}}\right]=\Gamma_{11} \\
& \ln \left[\frac{\mu_{12}^{t}}{\sqrt{\mu_{10}^{t} \mu_{02}^{t}}}\right]=\Gamma_{12} \\
& \ln \left[\frac{\mu_{21}^{t}}{\sqrt{\mu_{20}^{t} \mu_{01}^{t}}}\right]=\Gamma_{21} \\
& \ln \left[\frac{\mu_{22}^{t}}{\sqrt{\mu_{20}^{t} \mu_{02}^{t}}}\right]=\Gamma_{22} \\
& m_{2}^{t+1}=m_{1}^{t}-\mu_{11}^{t} \\
& f_{2}^{t+1}=f_{1}^{t}-\mu_{11}^{t}
\end{aligned}
$$

for all $t$. Given $\Gamma_{11}, \Gamma_{12}, \Gamma_{21}$ and $\Gamma_{22}$; a sequence of new entrants, $\left\{m_{1}^{t}, f_{1}^{t}\right\}$, for $t=0, \ldots$; and initial values, $\left\{m_{1}^{0}, f_{1}^{0}, m_{2}^{0}, f_{2}^{0}\right\}$, the sequence of marital behavior $\left\{\mu_{11}^{t}, \mu_{12}^{t}, \mu_{21}^{t}, \mu_{22}^{t}\right\}$ can be solved for $t=0, \ldots$ Given data from two adjacent time periods, $t$ and $t+1, \Gamma_{11}, \Gamma_{12}$, $\Gamma_{21}$ and $\Gamma_{22}$ can be estimated using equations (67) to (70). Thus (67) to (72) constitute a dynamic MMF. Unlike static MMFs, the dynamic MMF is defined by a system of forward looking difference equations. The forward looking aspect of the marriage matching function is due to the assumption that market participants are forward looking and therefore future supplies will matter to their current decisions.

A constant $\Gamma_{i j}^{t}$ is not an innocuous assumption. Based on static models, CS has already shown that the gains to marriage have fallen substantially between the seventies and eighties in the US. Angrist and Evans (1999) and CS have shown that the legalization of abortion in the US in the early seventies substantially reduced the gains to marriage for young adults. ${ }^{22}$ 


\section{How does the marriage market clear? An empirical framework.}

BSV, summarized here, also shows that a time independent $\Gamma_{i j}^{t}$ is not plausible for China. If $\Gamma_{i j}^{t}$ is time varying, then one needs to specify the dynamic process for $\Gamma_{i j}^{t}$ in the dynamic MMF as well. Choo Siow (2007) provides preliminary estimates of a dynamic MMF with long lived agents and exogenous divorce, assuming $\Gamma_{i j}^{t}=\Gamma_{i j}$ and a time invariant distribution of new entrants.

\subsection{Analytic solution to a special case ca $^{23}$}

In general, the number of marriages of the dynamic MMF, equations (67) to (72), cannot be solved for analytically. We will consider a special case. Let preferences be time invariant, i.e. $\Gamma_{i j}^{t}=\Gamma_{i j}$. Since the sex ratio at birth is essentially one, let $f_{1}^{t}=m_{1}^{t}$. Finally, let there be no gender difference in marriage preferences, i.e. $\Gamma_{21}=\Gamma_{12}$. The appendix shows that:

\section{Proposition 12}

$$
\begin{aligned}
& \mu_{11}^{t}=\phi_{11}+a_{11} \mu_{11}^{t-1}+a_{12} \mu_{22}^{t-1}+\sum_{k=0}^{\infty} \lambda_{12}^{k+1} G_{12}(L) m_{1}^{t+k} \\
& \mu_{22}^{t}=\phi_{22}+a_{21} \mu_{11}^{t-1}+a_{22} \mu_{22}^{t-1}+\sum_{k=0}^{\infty} \lambda_{22}^{k+1} G_{22}(L) m_{1}^{t+k}
\end{aligned}
$$

where $\lambda_{12}$ and $\lambda_{22}$ are between 0 and 1 , so that the infinite sums converge.

The equilibrium numbers of $\{i, j\}$ marriages depend on past number of marriages, past, present and future population supplies. The past numbers of marriages and past numbers of young population supply matters because they give the numbers of available old individuals in the current period. Future young population supplies matter because they predict how many young adults will be around in the next period, which will affect the decisions of the current adults. Standard static marriage matching functions on depend on current supplies 


\section{How does the marriage market clear? An empirical framework.}

of each type of individual (young and old). The dynamic MMF also includes future supplies of the young.

\section{Conclusion}

This paper presents the CS MMF. This framework can be extended to incorporate the collective intra-household allocation model. It also can be used to develop dynamic MMFs. The paper also provides different empirical applications.

Much remains to be done. Analytically, the substitution properties in the CS model remains to be worked out. The question of global uniqueness of the CS model and its generalizations needs to be addressed. The framework should be extended to include incomplete contracting and endogenous marital dissolution. ${ }^{24}$

The estimation and testing of the collective marriage matching model is just beginning. Estimating a dynamic MMF with time varying preference parameters and population supplies is an important goal. Estimating this class of models using internet dating data as in Hitsch, et. al. (2008) is also promising. Finally, the empirical framework here assumes away the problem of unobserved heterogeneity. Empirical bilateral matching models with unobserved heterogeneity on both sides of the market need to be developed. 


\section{How does the marriage market clear? An empirical framework.}

\section{References}

Angrist, Josh (2002) 'How do sex ratios affect marriage and labor markets? Evidence from America's second generation,' Quarterly Journal of Economics 117, 997-1038

Angrist, Joshua D. and William N. Evans (1999) 'Schooling and labor market consequences of the 1970 state abortion reforms,' Research in Labor Economics 18, 75-113

Becker, Gary S (1973) 'A theory of marriage: part I,' Journal of Political Economy 81, $813-46$

Becker, Gary S (1974) 'A theory of marriage: part II,' Journal of Political Economy 82, S11-S26

Becker, Gary S (1991) A Treatise on the Family (Cambridge, Mass.: Harvard University Press)

Bergstrom, Theodore (1997) 'A survey of theories of the family,' In Handbook of Population and Family Economics, ed. Mark R. Rosenzweig and Oded Stark (Amsterdam: Elsevier Science) 1A, 21-74

Bergstrom, Theodore and David Lam (1994) 'The effects of cohort size on marriage markets in twentieth century Sweden,' In The Family, the Market, and the State in Ageing Societies, ed. John Ermisch and Naohiro Ogawa (Oxford: Oxford University Press) 46-63

Bhrolchain, Maire Ni (2001) 'Flexibility in the marriage market,' Population: An English Selection 13, 9-47

Blundell, Richard, Pierre-Andre Chiappori and Costas Meghir (2005) 'Collective labor supply with children,' Journal of Political Economy 113, 1277-1306 


\section{How does the marriage market clear? An empirical framework.}

Blundell, Richard, Pierre-Andre Chiappori, Thierry Magnac and Costas Meghir (2007) 'Collective labour supply: heterogeneity and non-participation,' Review of Economic Studies $74,417-445$

Botticini, Maristella and Aloysius Siow (2003) 'Why dowries?' American Economic Review $93,1385-1398$

Botticini, Maristella and Aloysius Siow (2007) 'Are there increasing returns in marriage markets?' University of Toronto working paper, http://www.economics.utoronto. ca/siow/papers/IRSDec2007.pdf

Brandt, Loren, Aloysius Siow and Carl Vogel (2008) 'How flexible is the marriage market? Evidence from famine born cohorts in China,' University of Toronto Working Paper, http:

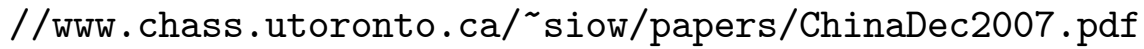

Chiappori, Pierre-Andre (1988) 'Rational household labor supply', Econometrica 56, 6390

Chiappori, Pierre-Andre (1992) 'Collective labor supply and welfare,' Journal of Political Economy 100, 437-467

Chiappori, Pierre-Andre, Bernard Fortin and Guy Lacroix (2002) 'Marriage market, divorce legislation, and household labor supply,' Journal of Political Economy 110, 37-72

Chiappori, Pierre-Andre, Murat Iyigun and Yoram Weiss (2008) 'An assignment model with divorce and remarriage,' University of Colorado working paper, http: //stripe. colorado. edu/ iyigun/CIW030105.pdf, May

Choo, Eugene and Aloysius Siow (CS) (2006) 'Who marries whom and why,' Journal of 


\section{How does the marriage market clear? An empirical framework.}

Political Economy 114, 175-201.

Choo, Eugene and Aloysius Siow (2006a) 'Estimating a marriage matching model with spillover effects,' Demography 43, 463-488

Choo, Eugene and Aloysius Siow (2007) 'Lifecycle marriage matching: theory and evi-

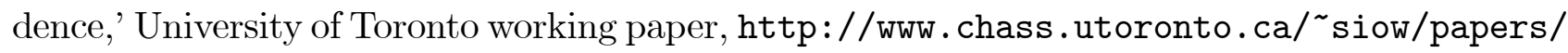
dynamics.pdf

Choo, Eugene, Shannon Seitz and Aloysius Siow (CSSa) 'Marriage matching, risk sharing and spousal labor supplies,' University of Toronto working paper, http://www. economics . utoronto.ca/siow, forthcoming

Choo, Eugene, Shannon Seitz and Aloysius Siow (CSSb) 'An empirical model of intrahousehold allocations and marriage matching,' University of Toronto working paper, http: //www. economics.utoronto.ca/siow, forthcoming

Dagsvik, John K (2000) 'Aggregation in matching markets,' International Economic Review $41,27-57$

Dagsvik, John K., Ane S. Flaatten and Helge Brunborg (2001) 'A behavioral two-sex marriage model,' Mathematical Population Studies 9, 97-121

Donni, Olivier (2005), 'A bibliography of the literature on collective and strategic models of household behavior,' Université de Cergy-Pontoise report, http://www.u-cergy.fr/ rech/pages/donni/BiblioColl.pdf, September 14

Esteve, Albert and Anna Cabré (2004) 'Marriage squeeze and changes in family formation: historical comparative evidence in Spain, France and the United States in the twentieth 


\section{How does the marriage market clear? An empirical framework.}

century,' Population Association of America 2004 Annual Meeting Program

Fox, Jeremy T. (2007) 'Estimating matching games with transfers,' University of Chicago working paper, http://home.uchicago.edu/ ${ }^{\text {fox }} /$ media/foxmatching-2.pdf, February

Francis, Andrew M. (2007) 'Sex ratios and the red dragon: using the Chinese communist revolution to explore the effect of the sex ratio on women and children in Taiwan,' Emory University, November 29

Goldin, Claudia, and Lawrence Katz (2002) 'The power of the pill: oral contraceptives and women's career and marriage decisions,' Journal of Political Economy 110, 730-70

Gorgens, Tue, Xin Meng and Rhema Vaithianathan (2005) 'Stunting and selection effects of famine: A case study of the great Chinese famine,' Australian National University, working paper, May

Grossbard-Shectman, Shoshana (1993) On the Economics of Marriage: A Theory of Marriage, Labor and Divorce (Boulder: Westview Press)

Hamilton, Gillian and Aloysius Siow (2007) 'Class, gender and marriage,' Review of Economic Dynamics 10, 549-575

Hitsch, Guenter J., Ali Hortacsu and Dan Ariely (2008) 'Matching and sorting in online dating,' available at SSRN: http://ssrn.com/abstract=1113243, March 1

Leslie, P. H. (1945) 'On the use of matrices in certain population mathematics,' Biometrika 33, 183-212

Lundberg, Shelly and Robert A. Pollak (1996) 'Bargaining and distribution in marriage,' Journal of Economic Perspectives 10, 139-158 


\section{How does the marriage market clear? An empirical framework.}

Lundberg, Shelly and Robert A. Pollak (2003) 'Efficiency in marriage,' Review of Economics of the Household 1, 153-167

McFadden, Daniel (1974) 'Conditional logit analysis of qualitative choice behavior,' In Frontiers in Econometrics, ed. P. Zarembka (New York: Academic Press) 105-142

Peters, Michael and Aloysius Siow (2002) 'Competing premarital investments,' Journal of Political Economy 110, 592-608

Pollak, Robert (1990) 'Two-sex population models and classical stable population theory,' In Convergent Issues in Genetics and Demography, ed. Julian Adams et. al. (New York: Oxford University Press) 317-33

Pollak, Robert (1990a) 'Two-sex demographic models,' Journal of Political Economy 98, $399-420$

Pollard, John H. and Charlotte Hohn (1993-94) 'The interaction between the sexes,' Zeitschrift fur Bevolkerungswissenschaft 19, 203-08

Pollard, John H. (1997) 'Modelling the interaction between the sexes,' Mathematical and Computer Modelling 26, 11-24

Porter, Maria (2007) 'The effects of sex ratio imbalance in China on marriage and household decisions,' University of Chicago working paper, http://home.uchicago.edu/ mporter/chinajuly2207.pdf

Preston, Samuel H. and Alan Thomas Richards (1975) 'The influence of women's work opportunities on marriage rates,' Demography 12, 209-222

Qian, Zhenchao and Sam Preston (1993) 'Changes in American marriage, 1972 to 1987: 
How does the marriage market clear? An empirical framework.

availability and forces of attraction by age and education,' American Sociological Review 58, 482-495

Schoen, Robert (1981) 'The harmonic mean as the basis of a realistic two-sex marriage model,' Demography 18, 201-216

Seitz, Shannon (2008). "Accounting for Racial Differences in Marriage and Employment." Boston College manuscript, June

Siow, Aloysius (1998) 'Differential fecundity, markets, and gender roles,' Journal of Political Economy 106, 334-354

Vermeulen, Frederic (2002) 'Collective household models: principles and main results,' Journal of Economic Surveys 16, 533-564

Waite, Linda J. et. al., ed. (2000) The Ties that Bind: Perspectives on Marriage and Cohabitation (Hawthorne, New York: Aldine de Gruyter)

Weiss, Yoram (1997) 'The formation and dissolution of families: why marry? Who marries whom? And what happens upon divorce,' In Handbook of Population and Family Economics, ed. Mark R. Rosenzweig and Oded Stark (Amsterdam: Elsevier Science) 1A, $81-124$ 


\section{Appendix A}

\section{Appendix $^{25}$}

With these restrictions, (67) to (72) reduce to:

$$
\begin{aligned}
\frac{\mu_{11}^{t}}{m_{1}^{t}-\mu_{12}^{t}-\mu_{11}^{t}}\left[\frac{m_{1}^{t}-\mu_{11}^{t}}{m_{1}^{t}-\mu_{11}^{t}-\mu_{22}^{t+1}-\mu_{21}^{t+1}}\right] & =\gamma_{11}=\exp \Gamma_{11} \\
\frac{\left(\mu_{12}^{t}\right)^{2}}{\left(m_{1}^{t}-\mu_{12}^{t}-\mu_{11}^{t}\right)\left(m_{1}^{t-1}-\mu_{11}^{t-1}-\mu_{22}^{t}-\mu_{12}^{t}\right)} & =\gamma_{12}=\exp 2 \Gamma_{12} \\
\frac{\mu_{22}^{t}}{m_{1}^{t}-\mu_{12}^{t}-\mu_{11}^{t}} & =\gamma_{22}=\exp \Gamma_{22} \\
\mu_{12}^{t} & =\mu_{21}^{t}
\end{aligned}
$$

We can solve for the steady state number of marriages when $m_{1}^{t}=m$ :

$$
\begin{aligned}
& \mu_{11}=m_{1} \frac{\gamma_{11}}{\left(\sqrt{1+\gamma_{22}}+\sqrt{\gamma_{12}}\right)^{2}+\gamma_{11}} \\
& \mu_{22}=m_{1} \frac{\gamma_{22}\left(1+\sqrt{\frac{\gamma_{12}}{1+\gamma_{22}}}\right)}{\left(\sqrt{1+\gamma_{22}}+\sqrt{\gamma_{12}}\right)^{2}+\gamma_{11}} \\
& \mu_{21}=\mu_{12}=m_{1} \frac{\gamma_{12}\left(1+\sqrt{\frac{1+\gamma_{22}}{\gamma_{12}}}\right)}{\left(\sqrt{1+\gamma_{22}}+\sqrt{\gamma_{12}}\right)^{2}+\gamma_{11}}
\end{aligned}
$$

As expected, the steady state numbers of marriages are homogeneous of degree one in $m_{1}$. The steady state numbers of marriages are also uniquely determined by $m_{1}$ and the preference parameters $\gamma_{11}, \gamma_{12}$ and $\gamma_{22}$.

Working with the linearized system around the steady state, (73) to (76) can be reduced to a two equation first order difference equation system in $\mu_{11}^{t}$ and $\mu_{22}^{t} \cdot \mu_{12}^{t}$ can be obtained as a function of $\mu_{11}^{t}$ and $\mu_{22}^{t}$ via (75). Let $G_{i j}(L)$ denote a lag structure of length $\{i, j\}$.

Taking logs of (73) to (76): 


\section{How does the marriage market clear? An empirical framework.}

$$
\begin{aligned}
\ln \mu_{11}^{t}-\ln \left(m_{1}^{t}-\mu_{12}^{t}-\mu_{11}^{t}\right)+\ln \left(\mu_{10}^{t}+\mu_{12}^{t}\right)-\ln \left(m_{1}^{t}-\mu_{11}^{t}-\mu_{22}^{t+1}-\mu_{12}^{t+1}\right) & =\Gamma_{11} \\
2 \ln \mu_{12}^{t}-\ln \left(m_{1}^{t}-\mu_{12}^{t}-\mu_{11}^{t}\right)-\ln \left(m_{1}^{t-1}-\mu_{11}^{t-1}-\mu_{22}^{t}-\mu_{12}^{t}\right) & =2 \Gamma_{12} \\
\ln \mu_{22}^{t}-\ln \mu_{20}^{t} & =\Gamma_{22} \\
\ln \mu_{22}^{t}-2 \ln \mu_{12}^{t}+\ln \left(m_{1}^{t}-\mu_{12}^{t}-\mu_{11}^{t}\right) & =\Gamma_{22}-2 \Gamma_{12} \\
\mu_{10}^{t-1}+\mu_{12}^{t-1} & =m_{2}^{t} \\
m_{1}^{t}-\mu_{12}^{t}-\mu_{11}^{t} & =\mu_{10}^{t} \\
m_{1}^{t-1}-\mu_{11}^{t-1}-\mu_{22}^{t}-\mu_{12}^{t} & =\mu_{20}^{t}
\end{aligned}
$$

Linearization of the above gives:

$$
\begin{aligned}
0 & =\frac{\mu_{11}^{t}}{\mu_{11}}-\frac{m_{1}^{t}-\left(\frac{\mu_{12} \mu_{10}}{2 \mu_{10}+\mu_{12}}\right)\left(\frac{\mu_{22}^{t}}{\mu_{22}}+\frac{m_{1}^{t}-\mu_{11}^{t}}{\mu_{10}}\right)-\mu_{11}^{t}}{\mu_{10}}+\frac{m_{1}^{t}-\mu_{11}^{t}}{m_{2}} \\
- & \frac{m_{1}^{t}-\mu_{11}^{t}-\mu_{22}^{t+1}-\left(\frac{\mu_{12} \mu_{10}}{2 \mu_{10}+\mu_{12}}\right)\left(\frac{\mu_{22}^{t+1}}{\mu_{22}}+\frac{m_{1}^{t+1}-\mu_{11}^{t+1}}{\mu_{10}}\right)}{\mu_{20}} \\
0 & =2 \frac{\left(\frac{\mu_{12} \mu_{10}}{2 \mu_{10}+\mu_{12}}\right)\left(\frac{\mu_{22}^{t+1}}{\mu_{22}}+\frac{m_{1}^{t+1}-\mu_{11}^{t+1}}{\mu_{10}}\right)}{\mu_{12}}-\frac{m_{1}^{t+1}-\left(\frac{\mu_{12} \mu_{10}}{2 \mu_{10}+\mu_{12}}\right)\left(\frac{\mu_{22}^{t+1}}{\mu_{22}}+\frac{m_{1}^{t+1}-\mu_{11}^{t+1}}{\mu_{10}}\right)-\mu_{11}^{t+1}}{\mu_{10}} \\
& -\frac{m_{1}^{t}-\mu_{11}^{t}-\mu_{22}^{t+1}-\left(\frac{\mu_{12} \mu_{10}}{2 \mu_{10}+\mu_{12}}\right)\left(\frac{\mu_{22}^{t+1}}{\mu_{22}}+\frac{m_{1}^{t+1}-\mu_{11}^{t+1}}{\mu_{10}}\right)}{\mu_{20}} \\
0 & =\mu_{12}^{t}-\left(\frac{\mu_{12} \mu_{10}}{2 \mu_{10}+\mu_{12}}\right)\left(\frac{\mu_{22}^{t}}{\mu_{22}}+\frac{m_{1}^{t}-\mu_{11}^{t}}{\mu_{10}}\right)
\end{aligned}
$$

We can ignore the equation (79) when solving the two equation difference equation system in $\mu_{11}^{t}$ and $\mu_{22}^{t},(77)$ and (78). This two equation system may be written as:

$$
A \mu^{t+1}=B \mu^{t}+C z^{t}
$$


How does the marriage market clear? An empirical framework.

where $\mu^{t}=\left[\begin{array}{c}\mu_{11}^{t} \\ \mu_{22}^{t}\end{array}\right]$ and $z^{t}=G(L) m^{t}$

On simply picking up the coefficients from the above two equations we get the following matrices, $B$ :

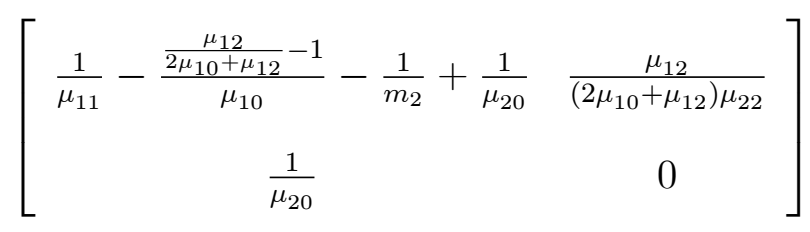

$A:$

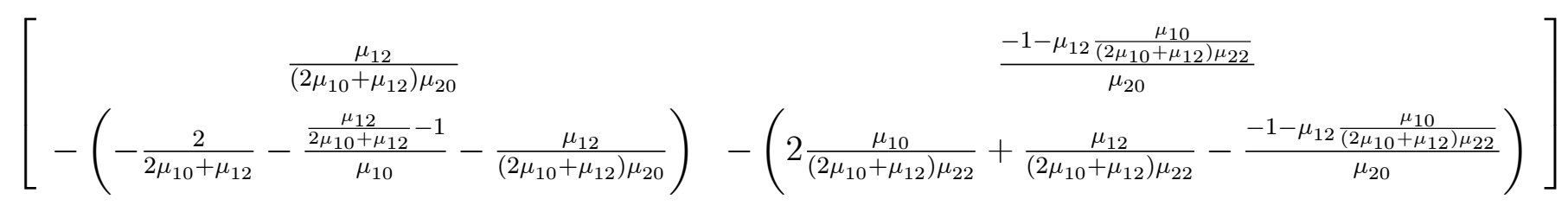

We can rewrite the two equation system as:

$$
\mu^{t+1}=A^{-1} B \mu^{t}+A^{-1} C z^{t}
$$

Now we can put $A^{-1} B=N^{-1} D N$ where $D$ is the diagonal matrix of eigenvalues of $A^{-1} B$ and $N$ are the eigenvectors of $A^{-1} B$. So we can write

$$
\begin{aligned}
\mu^{t+1} & =N^{-1} D N \mu^{t}+A^{-1} C z^{t} \\
N \mu^{t+1} & =D N \mu^{t}+N A^{-1} C z^{t}
\end{aligned}
$$

Let $N \mu^{t}=\nu^{t}$ and $\zeta^{t}=A^{-1} C z^{t}$. Then we have

$$
v^{t+1}=D \nu^{t}+\zeta^{t}
$$




\section{How does the marriage market clear? An empirical framework.}

Let $\lambda_{1}$ and $\lambda_{2}$ be the eigenvalues of $A^{-1} B$. So

$$
\begin{aligned}
& v_{1}^{t+1}=\lambda_{1} \nu_{1}^{t}+\zeta_{1}^{t} \\
& v_{2}^{t+1}=\lambda_{2} \nu_{2}^{t}+\zeta_{2}^{t}
\end{aligned}
$$

We will show that $\lambda_{1}>1$ and $0<\lambda_{2}<1$. Then we express:

$$
\begin{aligned}
& \nu_{1}^{t}=\sum_{k=0}^{\infty} \lambda_{1}^{-k-1} \zeta_{1}^{t+k} \\
& \nu_{2}^{t}=\sum_{l=0}^{\infty} \lambda_{2}^{l} \zeta_{2}^{t-l}
\end{aligned}
$$

Now since

$$
\begin{aligned}
& n_{11} \mu_{11}^{t}+n_{12} \mu_{22}^{t}=\nu_{1}^{t} \\
& n_{21} \mu_{11}^{t}+n_{22} \mu_{22}^{t}=\nu_{2}^{t}
\end{aligned}
$$

So

$$
\begin{aligned}
\mu_{11}^{t} & =\frac{n_{12}\left(n_{21} \mu_{11}^{t-1}+n_{22} \mu_{22}^{t-1}\right)-n_{22} \sum_{k=0}^{\infty} \lambda_{1}^{-k-1} \zeta_{1}^{t+k}}{n_{21} n_{12}-n_{11} n_{22}} \\
\mu_{22}^{t} & =\frac{-n_{11}\left(n_{21} \mu_{11}^{t-1}+n_{22} \mu_{22}^{t-1}\right)+n_{21} \sum_{k=0}^{\infty} \lambda_{1}^{-k-1} \zeta_{1}^{t+k}}{n_{21} n_{12}-n_{11} n_{22}}
\end{aligned}
$$

So we am done if we can show that $\lambda_{1}>1$ and $0<\lambda_{2}<1$.

Now $B^{-1} A$ is equal to:

$$
\left[\begin{array}{cc}
-\frac{\mu_{12}}{-2 m+\mu_{12}+2 \mu_{11}} & 2 \frac{-\mu_{12} m+\mu_{12} \mu_{11}+m^{2}-2 m \mu_{11}+\mu_{11}^{2}}{\left(-2 m+\mu_{12}+2 \mu_{11}\right) \mu_{22}} \\
\frac{-\left(2 m^{2}+2 \mu_{11}^{2}+2 \mu_{12} \mu_{11}-\mu_{12} m-4 m \mu_{11}\right) \mu_{22}}{\mu_{11}\left(-2 m+\mu_{12}+2 \mu_{11}\right)\left(-m+\mu_{11}\right)} & \frac{-4 m \mu_{11}^{2}+4 \mu_{12} \mu_{11}^{2}-10 m \mu_{11} \mu_{12}+8 m^{2} \mu_{11}+3 \mu_{12}^{2} \mu_{11}-4 m^{3}-2 \mu_{12}^{2} m+6 m^{2} \mu_{12}}{\left(-2 m+\mu_{12}+2 \mu_{11}\right) \mu_{12} \mu_{11}}
\end{array}\right]
$$

Substituting in the steady state values, the eigenvalues of $B^{-1} A$ are in the form of $\frac{1}{2 \gamma_{12} \gamma_{11}}(a+2 \sqrt{b})$ and $\frac{1}{2 \gamma_{12} \gamma_{11}}(a-2 \sqrt{b})$ where A and B are the following: 


\section{How does the marriage market clear? An empirical framework.}

$$
\begin{aligned}
a & =2 \gamma_{12} \gamma_{11}+2 \sqrt{\gamma_{12}} \gamma_{11} \sqrt{\left(1+\gamma_{22}\right)}+4 \gamma_{22} \gamma_{12}+4 \gamma_{12}+2\left(\sqrt{\gamma_{12}}\right)^{3} \sqrt{\left(1+\gamma_{22}\right)} \\
& +2 \sqrt{\gamma_{12}} \sqrt{\left(1+\gamma_{22}\right)} \gamma_{22}+2 \sqrt{\left(1+\gamma_{22}\right)} \sqrt{\gamma_{12}} \\
b & =\gamma_{12}+2 \gamma_{11} \gamma_{12}+3 \gamma_{12} \gamma_{22}+4 \gamma_{11} \gamma_{12} \gamma_{22}+6 \gamma_{12}^{2}+\gamma_{12}^{3}+6 \gamma_{11} \gamma_{12}^{2}+\gamma_{11}^{2} \gamma_{12}+3 \gamma_{12} \gamma_{22}^{2} \\
& +12 \gamma_{12}^{2} \gamma_{22}+\gamma_{12} \gamma_{22}^{3}+\gamma_{12}^{3} \gamma_{22}+2 \gamma_{11} \gamma_{12} \gamma_{22}^{2}+6 \gamma_{11} \gamma_{12}^{2} \gamma_{22}+\gamma_{11}^{2} \gamma_{12} \gamma_{22}+6 \gamma_{12}^{2} \gamma_{22}^{2} \\
& +4 \gamma_{12}^{\frac{3}{2}} \sqrt{\gamma_{22}+1}+4 \gamma_{12}^{\frac{5}{2}} \sqrt{\gamma_{22}+1}+6 \gamma_{11} \gamma_{12}^{\frac{3}{2}} \sqrt{\gamma_{22}+1}+2 \gamma_{11} \gamma_{12}^{\frac{5}{2}} \sqrt{\gamma_{22}+1}+8 \gamma_{12}^{\frac{3}{2}} \gamma_{22} \sqrt{\gamma_{22}+1} \\
& +4 \gamma_{12}^{\frac{5}{2}} \gamma_{22} \sqrt{\gamma_{22}+1}+6 \gamma_{11} \gamma_{12}^{\frac{3}{2}} \gamma_{22} \sqrt{\gamma_{22}+1}+2 \gamma_{11}^{2} \gamma_{12}^{\frac{3}{2}} \sqrt{\gamma_{22}+1}+4 \gamma_{12}^{\frac{3}{2}} \gamma_{22}^{2} \sqrt{\gamma_{22}+1}
\end{aligned}
$$

We need to show that the first eigenvalue is greater than 1 and the second is less than 1 but greater than zero. The first is self evident, just taking the multiplier $\frac{1}{2 \gamma_{12} \gamma_{11}}$ and multiplying it with $a$ yields the desired result, we needn't even use $2 \sqrt{b}$ for this. Now moving to the second part, showing that second lies between 0 and 1.

First let's show that $(a-2 \sqrt{b})>0$ or $A^{2}-4 B>0$. Evaluating the left side we get $a^{2}-4 b=4 \gamma_{11}^{2} \gamma_{12}^{2}>0$

The above shows that eigenvalue is greater than zero. Now we need to show that its less than one or $\left(a-2 \gamma_{12} \gamma_{11}\right)^{2}-4 b<0$. Let me evaluate the left side:

$$
\begin{aligned}
\left(a-2 \gamma_{12} \gamma_{11}\right)^{2}-4 b & =-16 \gamma_{11} \gamma_{12}^{2}-16 \gamma_{11} \gamma_{12}^{2} \gamma_{22}-8 \gamma_{11} \gamma_{12}^{\frac{3}{2}} \sqrt{\gamma_{22}+1}-8 \gamma_{11} \gamma_{12}^{\frac{5}{2}} \sqrt{\gamma_{22}+1} \\
& -8 \gamma_{11} \gamma_{12}^{\frac{3}{2}} \gamma_{22} \sqrt{\gamma_{22}+1}-8 \gamma_{11}^{2} \gamma_{12}^{\frac{3}{2}} \sqrt{\gamma_{22}+1}
\end{aligned}
$$

All terms are negative, hence the proof. 


\section{How does the marriage market clear? An empirical framework.}

Lead footnote: 2008 Canadian Economic Association presidential address. I like to thank all my co-authors on my research on the family: Loren Brandt, Maristella Botticini, Eugene Choo, Gillian Hamilton, Michael Peters, Shannon Seitz, Carl Vogel, Wang Hui and Xiaodong Zhu. I also owe intellectual debts to my present and past colleagues, seminar participants and students in my graduate labor classes. I also had good luck to stand on the shoulders of my teachers at the University of Chicago. I thank SSHRC for continuous financial support over the last fifteen years, without which, this research program would not have been possible. The University of Toronto has been a great environment to work in.

\section{Notes}

${ }^{1}$ Becker's classic papers on the marriage market (1973,1974; summarized in his 1991 book) focused on these issues. Bergstrom (1997); Weiss (1997) and Waite (2000) survey the recent literature.

${ }^{2}$ Even when observed, Botticini and Siow (2003) cautions against interpreting dowries solely as transfers which clear the marriage market.

${ }^{3}$ Economists have proposed other behaviorally motivated marriage matching models with strong apriori identifying restrictions. E.g. Del Bocca and Flinn (2006); Hamilton and Siow (2007); Wong (2003). Exceptions include Fox (2007) and Hitsch, et. al. (2008).

4 "Models that analyze bargaining within existing marriages can give only an incomplete picture of the determinants of the well-being of men and women. The marriage market is an important determinant of distribution between men and women. At a minimum, the marriage market determines who marries and who marries whom." Lundberg and Pollak (1996).

${ }^{5}$ Seitz 2008 first proposes this statistic in a related context.

${ }^{6}$ This discussion builds on Pollak (1990); Pollard (1993,1997).

${ }^{7}$ Pollak (1990a) is an important contribution to this research agenda. 


\section{How does the marriage market clear? An empirical framework.}

${ }^{8}$.... the frustrating search for a mathematically tractable and sociologically realistic "marriage function". (Preston and Richards (1975))

${ }^{9}$ Dagsvik (2000); Dagsvik et. al. (2001) have a closely related model. See CS for a comparison.

${ }^{10} \varepsilon \sim E V(0,1)$, with the cumulative distribution given by $F(\varepsilon)=e^{-e^{-\varepsilon}}$. $\mathbf{E} \varepsilon=c$ which is Euler's constant $\approx 0.577$.

${ }^{11}$ Porter (2007) has a related study. Also see Bergstrom and Lam (1994) and Francis (2007).

${ }^{12}$ They were born at least 6 years before the famine began.

${ }^{13}$ Also market tightness for mixed race couples which include white spouses are very different from own race couples because there are so many more whites than other races in the data. So we would need to have separate coefficients on tightness for each mixed race couples.

${ }^{14}$ This is the difference between individual observations, where $80 \%$ of the marriages are among white couples, and observations by cell.

${ }^{15}$ To be precise, we measure the fraction of individuals with non-positive non-labor income rather than zero non-labor income.

${ }^{16}$ I also estimated the supply of log of weeks worked per year. The estimated elasticities were similar to that for usual hours of work per week.

${ }^{17}$ For each $\{i, j, s\}$ marriage, I use sex ratios by age, by race, and by education as substitutes' sex ratios.

${ }^{18}$ Blundell, et. al. 2007 provides an alternative interpretation.

${ }^{19}$ The instrumental variable results presented here are quantitatively and qualitatively similar to the OLS results which raises a question as to how powerful the instruments are.

${ }^{20}$ The emprical industrial organization literature usually rejects the basic logit specification when estimating discrete demand models.

${ }^{21} R$ are distributional factors in CFL terminology. They are factors, other than determinants of preferences and budget constraints in $\{i, j, s\}$ marriages, which affect husband's power. Due to the set of marriages that they consider, CFL and CSSb work with $\tau(R, W, w, A)$ notation directly.

${ }^{22}$ Also see Goldin and Katz (2002). 


\section{How does the marriage market clear? An empirical framework.}

${ }^{23}$ This section applies standard techniques in rational expectations models to the problem at hand.

${ }^{24}$ E.g. Lundberg and Pollak (2003); Peters and Siow (2002); Chiappori, Iyigun and Weiss (2008) have results under restrictive marriage matching assumptions.

${ }^{25}$ Shashi Khatri aided in these derivations. 
How does the marriage market clear? An empirical framework.

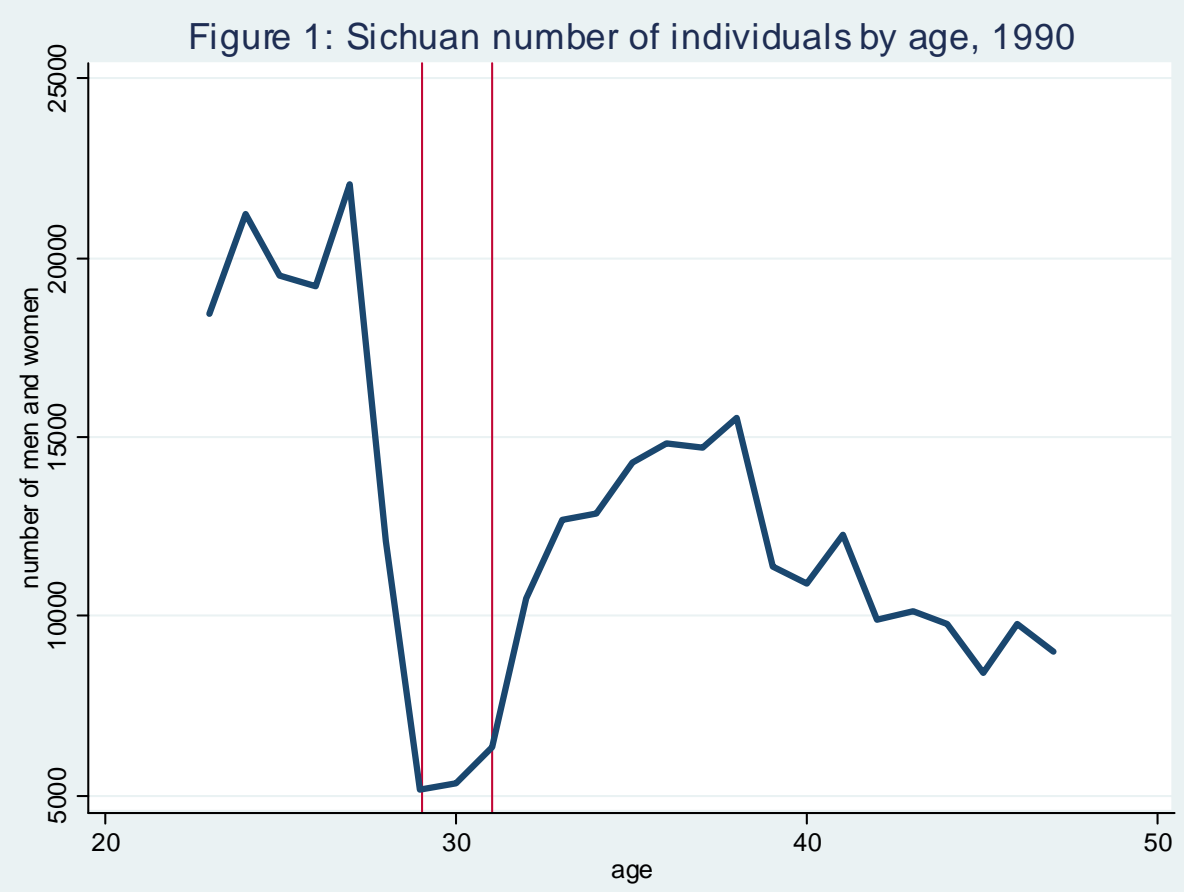

Figure 2: Sichuan sex ratios female ages, 1990

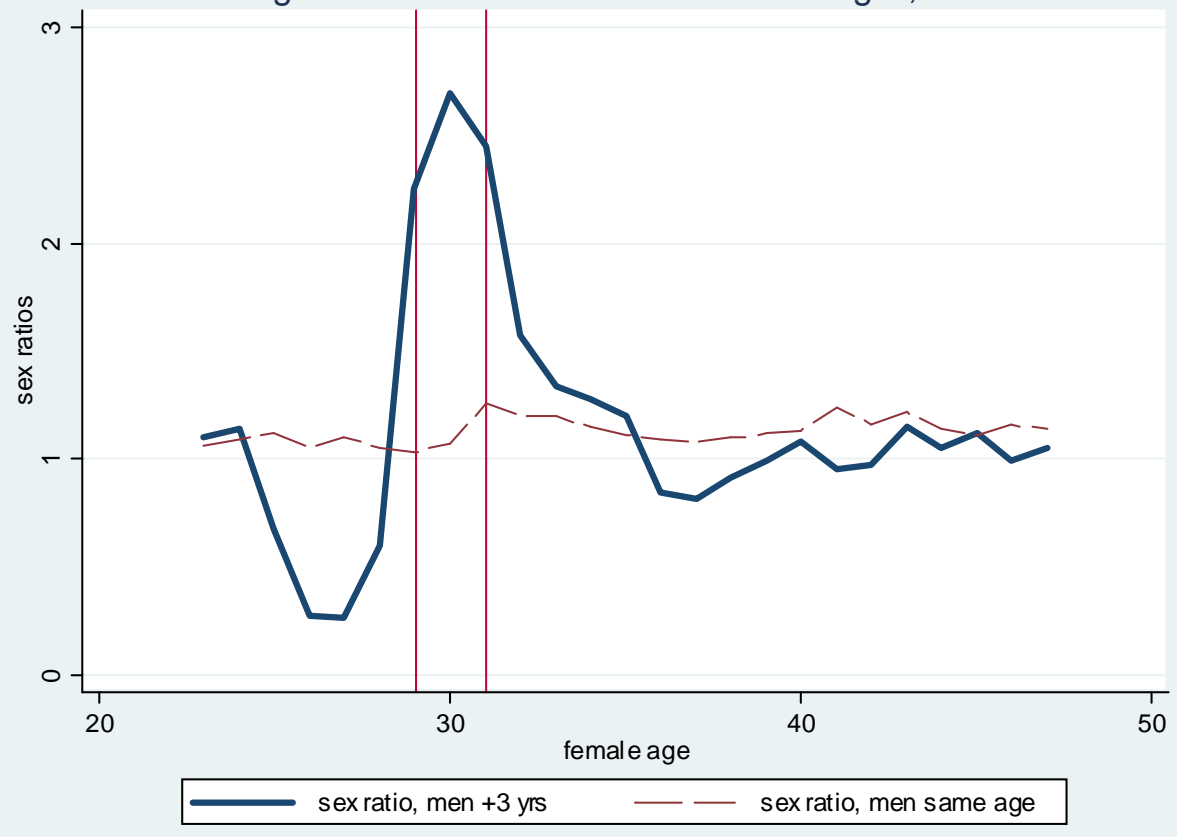


How does the marriage market clear? An empirical framework.

Figure 3: Predicted and actual 1990 Sichuan male marriage rates

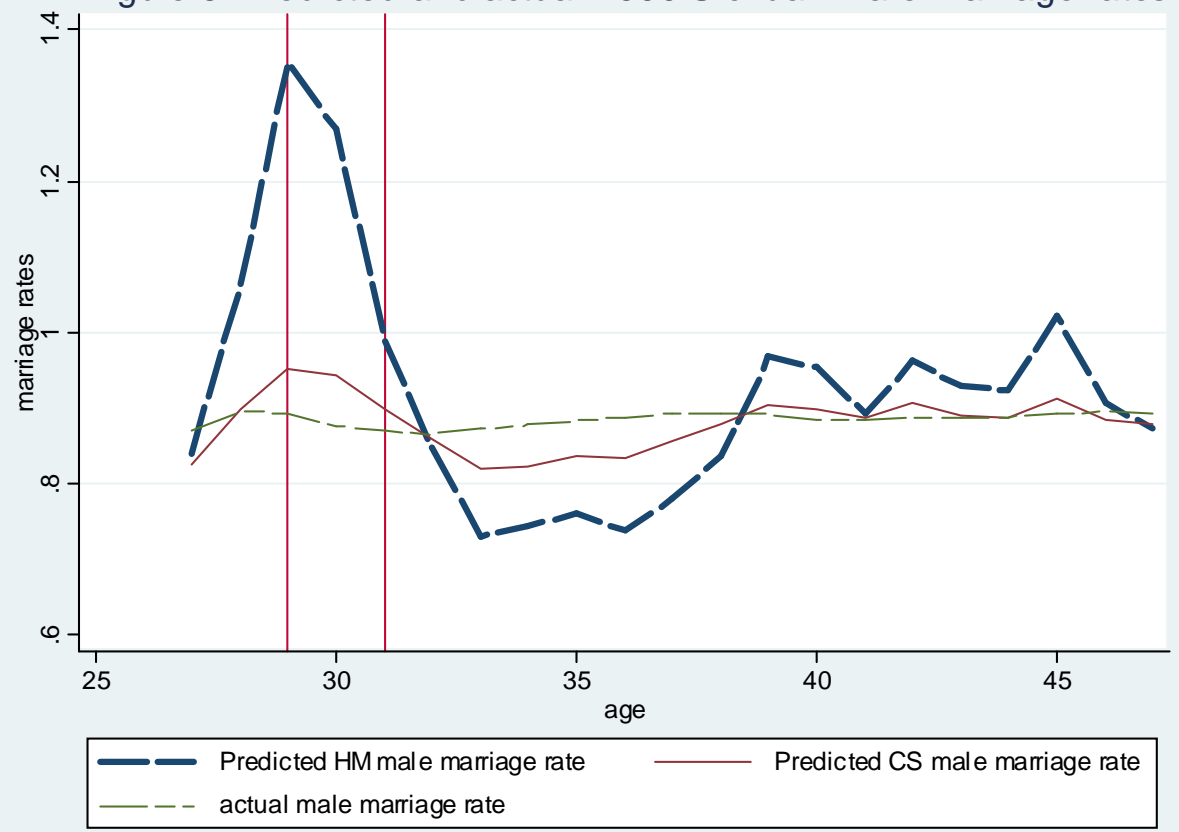

Figure 4: Predicted and actual 1990 Sichuan female marriage rates

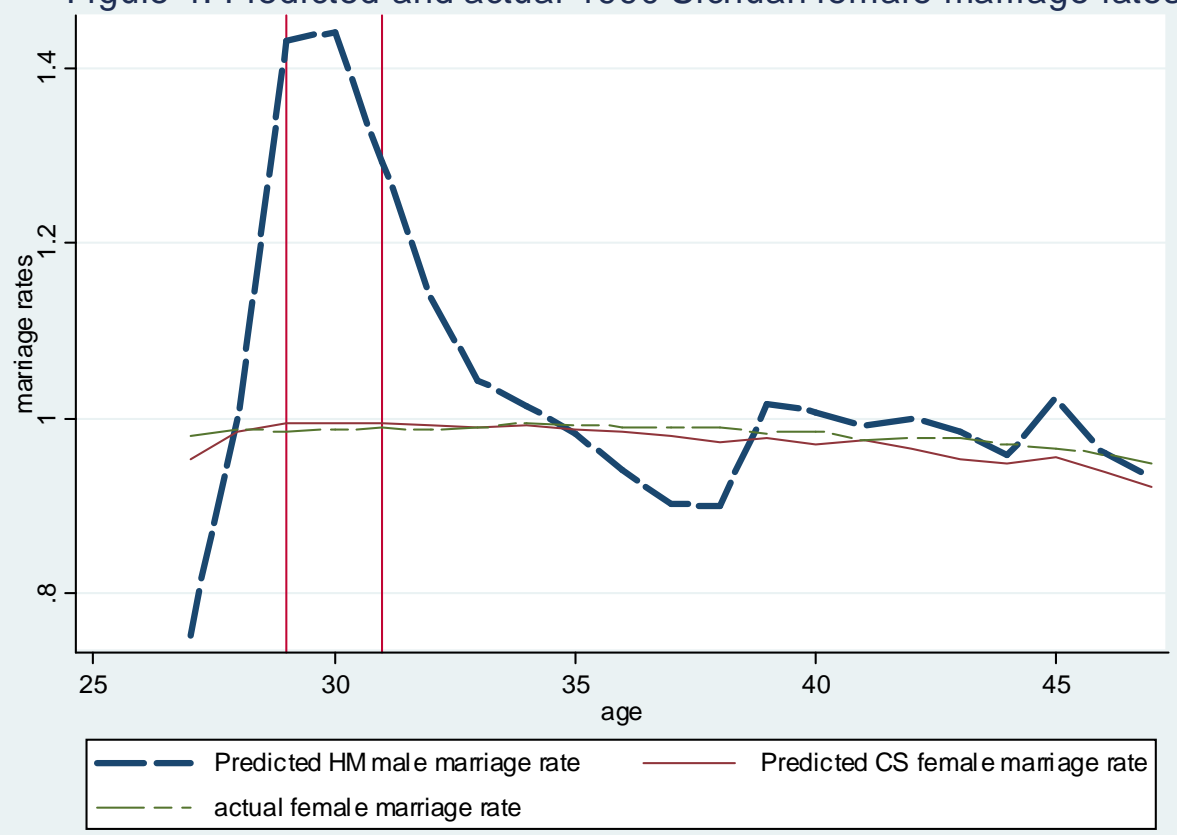


Table 1: Effects of market tightness on log odds of labor force participation of spouses

\begin{tabular}{|l|l|l|l|l|l|l|}
\hline & $(1)$ & $(2)$ & $(3)$ & $(4)$ & $(5)$ & $(6)$ \\
\hline & Wives & Wives & Wives & Husbands & Husbands & Husbands \\
\hline$T_{i j}$ & 0.330 & -0.176 & -0.167 & -0.034 & 0.145 & 0.015 \\
\hline & $(0.016)^{* *}$ & $(0.032)^{* *}$ & $(0.065)^{* *}$ & $(0.019)$ & $(0.041)^{* *}$ & $(0.072)$ \\
\hline & & & & & & \\
\hline Observations & 2330 & 2330 & 2330 & 2083 & 2083 & 2083 \\
\hline R-squared & 0.229 & 0.480 & 0.545 & 0.138 & 0.582 & 0.645 \\
\hline States & $\mathrm{X}$ & $\mathrm{X}$ & $\mathrm{X}$ & $\mathrm{X}$ & $\mathrm{X}$ & $\mathrm{X}$ \\
\hline Labor mark & & $\mathrm{X}$ & $\mathrm{X}$ & & $\mathrm{X}$ & $\mathrm{X}$ \\
\hline M type & & & $\mathrm{X}$ & & & $\mathrm{X}$ \\
\hline $\mathrm{F} \mathrm{type}$ & & & $\mathrm{X}$ & & & $\mathrm{X}$ \\
\hline $\begin{array}{l}1 \text { SD } T_{i j} \\
\text { increase }\end{array}$ & & -0.26 & & & 0.16 & \\
\hline
\end{tabular}

Table 2: Effects of market tightness on log usual hours worked per weeks of spouses

\begin{tabular}{|l|l|l|l|l|l|l|}
\hline & $(1)$ & $(2)$ & $(3)$ & $(4)$ & $(5)$ & $(6)$ \\
\hline & Wives & Wives & Wives & Husbands & Husbands & Husbands \\
\hline$T_{i j}$ & 0.037 & -0.028 & -0.044 & -0.003 & 0.018 & -0.002 \\
\hline & $(0.002)^{* *}$ & $(0.005)^{* *}$ & $(0.010)^{* *}$ & $(0.002)$ & $(0.003)^{* *}$ & $(0.008)$ \\
\hline & & & & & & \\
\hline Observations & 2322 & 2322 & 2322 & 2380 & 2380 & 2380 \\
\hline R-squared & 0.248 & 0.499 & 0.525 & 0.095 & 0.330 & 0.343 \\
\hline States & $\mathrm{X}$ & $\mathrm{X}$ & $\mathrm{X}$ & $\mathrm{X}$ & $\mathrm{X}$ & $\mathrm{X}$ \\
\hline Labor mark & & $\mathrm{X}$ & $\mathrm{X}$ & & $\mathrm{X}$ & $\mathrm{X}$ \\
\hline M type & & & $\mathrm{X}$ & & & $\mathrm{X}$ \\
\hline $\mathrm{F}$ type & & & $\mathrm{X}$ & & & $\mathrm{X}$ \\
\hline $\begin{array}{l}\text { 1 SD } T_{i j} \\
\text { increase }\end{array}$ & & -0.065 & & & 0.068 & \\
\hline
\end{tabular}

${ }^{\wedge}$ Fraction of SD increase of dependent variable due to $1 \mathrm{SD}$ increase in $T_{i j}$. 